\title{
Trio-clar Versus Portulaca Oleracea and/or Foeniculum Vulgare Extracts on Induced Gastric Ulcer in Adult Female Albino Rats. A Histological Study
}

\section{Original Article}

\author{
Amany Mesbah Mohammad Ali, Soad Kamal Mohammed Abd-Elgwwad, \\ Rehab Abd Allah Hasan and Mona Mohamed Abd-Elgalil
}

Department of Histology, Faculty of Medicine (Girls), Al-Azhar University, Cairo, Egypt

\begin{abstract}
Introduction: Gastric ulcer is a complex disease affecting the stomach. Non-Steroidal Anti-Inflammatory Drugs (NSAIDs) are the most common cause of gastric ulcers. Drugs used in gastric treatment induce side effects and drug interactions. Portulaca oleracea L. (purslane), Foeniculum Vulgare Mill (Fennel) are herbal remedies having gastro-protective effects. Aim of work: To assess the cytoprotective effects of trio-clar versus fennel and/or purslane on aspirin-induced gastric ulcer in adult female albino rats.

Materials and Methods: Forty-two adult female albino rats were divided into three main groups. Group I (control group). Group II (gastric ulcer), overnight fasted rats received aspirin solution $(300 \mathrm{mg} / \mathrm{kg} /$ day) orally by gastric tube. GroupIIIncorporated as the treated gastric ulcer group that was subdivided equally into four subgroups. GIIIa: gastric ulcer treated with Trio-clar. GIIIb: gastric ulcer treated with purslane extract at dose $750 \mathrm{mg} / \mathrm{kg}$. GIIIc: gastric ulcer treated with fennel extract at a dose of $300 \mathrm{mg} / \mathrm{kg}$. GIIId: gastric ulcer treated with a combined dose of purslane and fennel extract. Fundus of stomach specimens was prepared and examined using different histological techniques.

Results: Light microscopic study of the gastric ulcer group depicted severe mucosal injury in the form of ulcerative erosion, dilated distorted glandular architecture, damage of parietal and chief cells with vacuolated cytoplasm and pyknotic nuclei, congested blood vessels and inflammatory cellular infiltration. A reduction of combined Alcian blue and Periodic-Acid-Schiff reaction coupled to a significant increase in area percentage of collagen fibers observed upon aspirin administration. The ultrastructural assessment confirmed these distortions. The treated groups showed different degrees of improvement in the histological changes depicted previously with priority to the combined administration of purslane and fennel extracts.

Conclusion: Combined administration of purslane and fennel was more effective in enhancing the healing process than either purslane, fennel alone or trio-clar drug.
\end{abstract}

Received: 28 February 2020, Accepted: 10 March 2020

Key Words: Aspirin, foeniculum vulgare (fennel), gastric ulcer, portulaca oleracea (purslane), trio-clar.

Corresponding Author: Amany Mesbah Mohammad Ali, MSc, Department of Histology, Faculty of Medicine (Girls), Al-Azhar University, Cairo, Egypt, Tel.: +20 1002223212, E-mail: amany.histo99@yahoo.com

ISSN: 1110-0559, Vol. 43, No.4

\section{INTRODUCTION}

Peptic ulcers are the result of an imbalance between the gastroduodenal mucosal defence mechanisms and damaging forces of gastric acid and pepsin, superimposed with environmental injury or reduced immunologic agents. Several predisposing factors can frequently increase the risk for ulcers including family history, emotional stress, cigarette smoking, regular alcohol consumption, gut ischemia-reperfusion injury, chronic helicobacter pylori (H. pylori) infection and use of non-steroidal antiinflammatory drugs (NSAIDs) $)^{[1,2]}$.

Conventional NSAID either powdered form or even safety-coated tablet form is among the most frequently prescribed drug for relieving post-traumatic pain and inflammation; including rheumatoid arthritis and other musculoskeletal disorders ${ }^{[2]}$.
The susceptibility of the gastric mucosa to NSAIDinduced injury depends partly on the local cytotoxic mechanism via osmotic lysis ${ }^{[3]}$ and partly on cyclooxygenase suppression and inhibition of prostaglandinmediated protective functions, reducing blood flow and accumulation of oxygen free radicals ${ }^{[4]}$.

The goal of therapy for peptic ulcer disease is to relieve symptoms, reduce gastric acidity and coat ulcer craters to prevent acid and pepsin from penetrating the ulcer base and provide a prostaglandin analogue. Moreover, removing most of the environmental factors such as emotional stress, NSAID and smoking prevent recurrences or complications of the gastric ulcer ${ }^{[5]}$.

The medical management of peptic ulcer disease employed various antiulcer drugs which interfere with normal physiological control of acid secretion and 
effectively block the final common pathway of acid production. Although these drugs are usually effective, treatment should continue life-long ${ }^{[6]}$.

Trio-clar is one of the most recent drugs to manage and cure NSAID-induced gastric ulcer by neutralization or reduction of gastric acid ${ }^{[7,8]}$.

Using herbal medicines is beneficial cost-effective natural remedies and economically available ${ }^{[9]}$. Moreover, the natural effective ingredients cause biological balance and prevent drug accumulation in the body ${ }^{[10]}$.

Portulaca oleracea L. (purslane) is reported to be an edible plant rich in $\alpha$-linolenic acid and s-carotene, several types of vitamins and minerals, unsaturated fatty acids and polyphenols ${ }^{[11]}$. Purslane is healthy food for patients with cardiovascular diseases and is widely used as a traditional Chinese herbal medicine for alleviating pain with antibacterial and antifungal effects ${ }^{[12]}$.

Foeniculum Vulgare Mill (Fennel), is a well-known aromatic plant that is largely distributed all over the world for its high content of protein, oils such as palmitic acid, oleic acid, linoleic acid and petrocylic acid, vitamins and minerals with their potential benefits on human health ${ }^{[13]}$.

So, this study was designed to assess the Trio-clar effect versus purslane and or fennel in ameliorating the histological changes of aspirin-induced gastric ulcer in adult female albino rats.

\section{MATERIALS AND METHODS}

\section{Animals}

Forty-two adult female albino rats, 4-6 months old, weighing 160-200 g were used in the present study. They were obtained from Helwan breeding farm laboratory, Helwan, Egypt. They were settled in hygienic well ventilated stainless steel meshed cages at room temperature (25-27) with normal light-dark cycle with strict care and hygienic conditions at the animal house, Faculty of medicine for girls, Al-Azhar University, Cairo. All rats were allowed free access to water and rat chow diet. They were acclimated for one week before the beginning of the experiment. All the ethical protocols for animal treatment were followed according to the Research Ethics Committee (FMG-IRB), Faculty of Medicine (Girls), Al-Azhar University.

\section{Used reagents}

- Portulaca Oleracea (purslane) and Foeniculum Vulgare (fennel) extracts. The extracts were purchased from, Nawah scientific centre, Cairo, Egypt.

- Aspirin: A commercially available formulation of acetylsalicylic acid (ASA) was used (Aspirin enteric-coated tablets $100 \mathrm{mg}$; Sanofi-Synthelabo, France).
- Trio-clar drug: A commercially available formulation of Omeprazole $20 \mathrm{mg}+$ Tinidazole $500 \mathrm{mg}+$ Clarithromycin $500 \mathrm{mg}$ enteric-coated capsules; Al-Hikmapharma company, Cairo, Egypt.

\section{Purslane extract preparation}

Aqueous extract of portulaca olarecea was prepared by the maceration method. Briefly, $1500 \mathrm{ml}$ of distilled water were added to 300 grams of dried purslane powder in a sealed glass container and it was set aside for about $72 \mathrm{~h}$. The filtrated extract was concentrated in a rotary evaporator under reduced pressure at $55{ }^{\circ} \mathrm{C}$ and dried in a bath of warm water. The powder was dissolved in distilled water (DW) $(120 \mathrm{mg} / \mathrm{ml})$ and was given daily by orogastric tube at a dose of $750 \mathrm{mg} / \mathrm{kg}^{[14,15]}$.

\section{Fennel extract preparation}

Foeniculum vulgare seeds were bought from the local market and were ground by an electrical mill. The aqueous extract was prepared by cold maceration of 100 gram of powder in $400 \mathrm{ml}$ of distilled water for $24 \mathrm{~h}$. Then, the extract was filtered, concentrated, dried in vacuum, and the residue was stored in a refrigerator at $2-8{ }^{\circ} \mathrm{C}$ for use in subsequent experiments. Dried F. Vulgare powder (3.2 g) was obtained from $100 \mathrm{~g} \mathrm{~F}$. Vulgare seeds. This powder was stored at $4{ }^{\circ} \mathrm{C}$ until required for use. The powder was dissolved in distilled water (DW) $(50 \mathrm{mg} / \mathrm{ml})$ and was given daily by oro-gastric tube at dose $300 \mathrm{mg} / \mathrm{kg}^{[16,17]}$.

\section{Induction of gastric ulcer}

Five tablets of aspirin were dissolved in $10 \mathrm{ml}$ of $1 \%$ carboxymethylcellulose (CMC) and gastric ulcer was induced by administering overnight fasted rats aspirin solution $(50 \mathrm{mg} / \mathrm{ml})$ using orogastric tube at a daily dose of $300 \mathrm{mg} / \mathrm{kg} / \mathrm{day}$ in the early morning for 5 consecutive days $^{[18,19]}$.

\section{Experimental design}

The animals were divided into three main groups:

- Group I (Control group): 12 rats of this group were further subdivided equally into two subgroups.

- Subgroup IA: each rat was given $1 \mathrm{ml}$ of distilled water once daily by gastric gavage for 6 weeks.

- Subgroup IB: each overnight fasted rat received $1 \mathrm{ml}$ of $1 \% \mathrm{CMC}$ (Aspirin vehicle) by oro-gastric tube once daily for 5 consecutive days.

Rats of each subgroup were sacrificed together at the same duration with the corresponding experimental groups.

- Group II (Aspirin-induced gastric ulcer): six overnight fasted rats received $1 \mathrm{ml}$ of aspirin solution $(50 \mathrm{mg} / \mathrm{ml})$ by gastric tube in the early morning for 
5 consecutive days, and then rats were sacrificed six hours after the last aspirin dose.

- Group III (Treated group): On the 5thday of aspirininduced gastric ulcer, 24 overnight fasted rats were further subdivided equally into the following four subgroups:

- GIII a (Trio-clar treated group): rats received $1 \mathrm{ml}$ aqueous Trio-clar at a dose of (Omeprazole $20 \mathrm{mg} \mathrm{kg}$ - Tinidazole 500 $\mathrm{mg} / \mathrm{kg}$ - Clarithromycin $500 \mathrm{mg} / \mathrm{kg}$ ) orally according to the table of Paget \& Barnes ${ }^{[20]}$ daily for six weeks.

- GIII b (purslane extract-treated group): Rats received $1 \mathrm{ml}(120 \mathrm{mg} / \mathrm{ml})$ of freshly prepared aqueous extract of purslane orally with rat chow diet daily following ulcer induction for 6 weeks.

- GIII c (fennel extract-treated group): Rats received $1 \mathrm{ml}(50 \mathrm{mg} / \mathrm{ml})$ of freshly prepared aqueous extract of fennel by orogastric tube with daily diet following ulcer induction till the end of the experiment ( 6 weeks).

- GIII d (combined purslane and fennel extracts treated group): Following aspirin-induced gastric ulcer; aqueous extracts of purslane and fennel were given orally with rat chow diet daily by the same dose and duration as GIIIb \& GIIIc respectively for 6 weeks.

- Six weeks from the induction of gastric ulcer, rats from control subgroup (IA) and GIII were sacrificed. While the animals of GIB, GII were sacrificed on the $5^{\text {th }}$ day, 6 hours after the last aspirin dose.

- The animals of all groups were weighed individually at the beginning of the experiment and the end just before collecting samples.

At the end of the experiment, the overnight fasted rats were anaesthetized by ether inhalation, the stomach from each animal was immediately excised, opened along the greater curvature, washed softly in $10 \%$ formalin to remove gastric content and stretched on a segment of cork with mucosal surface up in glass plat for macroscopic evaluation. The inner surface has been scanned, photographed to assess the extent of gastric lesions and hemorrhagic areas ${ }^{[21]}$.

\section{Histological study}

\section{Light microscopic study}

Stomach specimens (fundus and the upper portion of the body) were fixed in $10 \%$ formalin, dehydrated in ascending grades of ethyl alcohol, cleared in xylene, impregnated and embedded in paraffin wax. Sections ( $5 \mu \mathrm{m}$ thickness) were stained by Hematoxylin and eosin (H\&E) for studying the general structure ${ }^{[22]}$, combined
Alcian blue and PAS for mucus ${ }^{[23]}$, Masson's trichrome stain, for staining the collagen fibers ${ }^{[22]}$ and toluidine blue for staining mast cells ${ }^{[22]}$.

\section{Transmission electron microscopic study (TEM)}

Stomach specimens were taken while rats were still alive under light ether anaesthesia, small pieces of the body approximately $0.5 \mathrm{~mm}$ pieces were immediately fixed in $2.5 \%$ phosphate-buffered glutaraldehyde $(0.1 \mathrm{M}, \mathrm{pH} 7.4)$, post-fixed with $1 \%$ phosphate-buffered osmium tetroxide, and afterwards dehydrated in ascending grades of ethanol. After being immersed in propylene oxide, the specimens were embedded in the epoxy resin mixture. Semithin sections $(1 \mu \mathrm{m}$ thick) were stained with toluidine blue and examined by light microscope for proper orientation. Ultrathin sections $(50-60 \mathrm{~nm})$ were stained with uranyl acetate and lead citrate ${ }^{[24]}$. The sections were examined and photographed by JEOL 1010 transmission electron microscope (Jeol; Tokyo, Japan), at the Regional Center for Mycology and Biotechnology (RCMB), AL-Azhar University.

\section{Morphometric measurements}

All sections were examined by Lieca light microscope MDLSD coupled to a Leica digital camera transferred to the screen using a computerized image analyzer Leica Q500 MC program(Leica Microsystems Ltd, Cambridge, UK). Ten different non-overlapping randomly selected fields from a slide of each rat in all different experimental groups were examined to quantitatively evaluate the following:

- Parietal cells count in H\&E stained section at a magnification of 400 .

- The mean area percentage of collagen fibers in the lamina propria of mucosa between gastric glands and submucosa in Masson 's trichrome stain at a magnification of 200 .

- Mast cell count at the lamina propria and the submucosa in toluidine blue-stained sections at a magnification of 200 .

All histomorphometric measurements were carried out at the Regional Center for Mycology and Biotechnology (RCMB), AL-Azhar University.

\section{Statistical Analysis}

All statistical data were analyzed using Statistical Program for Social Science, version 20 (SPSS Inc., Chicago, Illinois, USA). Statistical significance was determined by one-way analysis of variance for differences between the means of different groups. Further analysis was carried out using Tukey's post-hoc test to compare the parameters in the different groups with each other. All data were expressed as mean \pm Standard Deviation (mean \pm SD) and a probability of $P<0.05$ was considered statistically significant ${ }^{[25]}$. 


\section{RESULTS}

\section{Gross appearance}

Macroscopic examination by the magnifying lens of the stomach of the control group revealed normal pink colouration of the gastric mucosa with prominent rugae (Figure 1a). Gastric mucosa of aspirin-induced gastric ulcer group (II) revealed brownish hemorrhagic spots and streaks with pallor of the surrounding gastric mucosa (Figure 1b). While, in the trio-clar treated group (IIIa), apparent normal gastric mucosa despite small tiny hyperemic spots were detected (Figure 1c). Obvious improvement was detected in the gastric ulcer treated with purslane extract (GIIIb), fennel extract (GIIIc) and with combined purslane \& fennel extract (GIIId) groups, in the form of normal pink gastric mucosa with prominent rugae that were more or less as the control group (Figures 1d-1f) respectively.

\section{Light microscopic results}

\section{Haematoxylin and eosin-stained sections results}

Examination of sections of group IA\& IB revealed the same histological picture.

Sections of the stomach of control group stained by $\mathrm{H} \& \mathrm{E}$ revealed normal histoarchitecture of the gastric mucosa, composed of epithelium that was interrupted by short narrow gastric pits, lamina propria and muscularis mucosa. The lamina propria was occupied by long tightly packed simple tubular or branched tubular fundic glands laying perpendicular to the surface. The fundic glands were differentiated into three regions; innermost isthmus, neck, and base regions (Figure 2a). The epithelial lining the surface, isthmus and the gastric pits was simple columnar surface (mucus-secreting) cells with pale cytoplasm and basal oval nuclei. The neck region was lined by groups of low columnar mucous neck cells with basal flattened nuclei and foamy cytoplasm interspersed with parietal cells (Figure 2b). Oxyntic or parietal cells appeared large pyramidal with deeply acidophilic cytoplasm and centrally located rounded vesicular nuclei (Figures 2b, 2c). Peptic or chief cells occupied the bases of the gastric glands and they were columnar cells recognized by basophilic cytoplasm and basally located rounded vesicular nuclei (Figure 2c).

The resulting mucosal lesions in aspirin-induced gastric ulcer group (II) revealed severe mucosal injury extended down to the muscularis mucosa in the form of distorted glandular histoarchitecture with widening of gastric pits and sloughing of epithelial cells at the ulcerated region into the gastric lumen (Figures 3a, 3b). Exfoliated epithelial cells appeared shrunken with deeply acidophilic cytoplasm and darkly stained nuclei. Some parietal and chief cells appeared vacuolated with darkly stained small nuclei despite that, some of them appeared deeply stained with darkly stained nuclei (Figures 3c, 3d). Moreover, congested blood capillaries along with diffuse inflammatory cellular infiltrations were prominent in the lamina propria in between the damaged fundic glands near the ulcerated area (Figures 3a, 3b, 3d).
Examination of $\mathrm{H} \& \mathrm{E}$ stained sections of the trio-clar treated gastric ulcer group (IIIa) revealed the nearly normal glandular architecture of the gastric mucosa comparable to the control group (Figure 4a). The apical parts of the fundic glands appeared lined with closely packed surface columnar mucous cells with basal oval vesicular nuclei, mucous neck cells with basal flattened nuclei more or less similar to control group. Near normal parietal cells with deep acidophilic cytoplasm and central rounded nuclei. Some vacuolated parietal cells were also observed (Figures $4 \mathrm{~b}, 4 \mathrm{c})$. Normal peptic cells with deep basophilic cytoplasm and basal rounded nuclei appeared lining the bases of the glands (Figure 4c). However, congested blood vessels in the lamina propria in between bases of fundic glands were evident (Figures 4a, 4c).

$\mathrm{H} \& \mathrm{E}$ stained sections of the gastric ulcer group treated with purslane extract (IIIb) revealed preservation of the regularly arranged closely packed gastric glands in spite of dilatation of the middle part of the glands (Figures 5a, 5c). Nearly normal surface columnar epithelial cells, mucus neck cells appeared more or less as the control group. Moreover, normal parietal cells with deep acidophilic cytoplasm and central rounded vesicular nuclei were evident. Some vacuolated parietal cells were also noticed (Figures 5b, 5c). Vacuolated peptic cells with deeply stained rounded nuclei were also present (Figure 5c).

Gastric ulcer group treated with fennel extract (IIIc) showed partial desquamation of the superficial epithelial lining overlaid the healed gastric ulcer, regular narrow straight fundic gland with widening of the gastric pits compared to control group. Exfoliated epithelial cells appeared shrinking with deeply acidophilic cytoplasm and darkly stained nuclei (Figures 6a, 6b). Some parietal cells appeared more or less as the control with deep acidophilic cytoplasm and central rounded vesicular nuclei while others had vacuolated cytoplasm (Figures 6b, 6c). Some chief cells with vacuolated cytoplasm and darkly stained nuclei appeared at the basal part of the fundic glands (Figure 6c). Congested blood vessels in the lamina propria in between bases of fundic glands were also evident (Figures 6a, 6c).

Interestingly, $\mathrm{H} \& \mathrm{E}$ stained sections of the gastric ulcer group treated with combined purslane and fennel extracts (IIId) revealed marked improvement in the glandular architecture of the gastric mucosa opened on the luminal surface by short narrow gastric pits (Figure 7a). Intact surface epithelial cells and mucous neck cells were closely similar to the control group (Figure $7 b$ ). Numerous normal parietal cells with deep acidophilic cytoplasm and central rounded nuclei distributed throughout the gland despite few vacuolated parietal cells were noticed. The chief cells lined the bases of the glands were mostly normal with basophilic cytoplasm and basal rounded nuclei along with few vacuolated peptic cells (Figures $7 b, 7 c$ ). Congested blood vessels were still evident in the lamina propria inbetween intact fundic glands (Figure 7b). 
Combined Alcian blue and Periodic acid chief stained sections results

Control group revealed continuous intense PAS-positive (+ve) magenta red mucus film covered the mucosal surface, pits, superficial isthmus and the body regions of the gland. Alcian blue +ve reaction appeared in the surface, deeper part of the gastric pit, isthmus and the neck regions

(Figure 8a). Examination of aspirin-induced gastric ulcer group (II) revealed complete absence of reactions in the distorted ulcerated region. While the nearby intact gastric mucosa showed positive alcian blue \& PAS reactions (Figure 8b).

Trio-clar treated group (IIIa) revealed strong PASpositive film of mucus at the reconstructed surface cells, superficial isthmus and the body region as well as +ve alcian blue reaction on the surface, isthmus and neck regions more or less as the control (Figure 8c). While, combined alcian blue and periodic acid chief stained sections of the gastric ulcer group treated with purslane extract (IIIb) appeared more or less as the control despite more prominent alcian blue positive reaction at the basal part of the gland compared to the control group was noticed (Figure 8d). Interestingly, gastric ulcer group treated with fennel extract (IIIc) revealed positive reactions at the intact region of the fundic glands despite interrupted mucus film on the distorted portion of the surface epithelium. Alcian blue positive reaction on the intact surface, isthmus and neck regions could be observed (Figure 8e). Alcian blue and PAS reactions in the gastric ulcer group treated with a combination of both purslane and fennel extracts (IIId) closely resembled the control group (Figure 8f).

\section{Masson's trichrome stained sections results}

Control group revealed fine dispersion of few collagen fibers in the thin lamina propria, extended mostly between the bases of the fundic glands and in the submucosa (Figure 9a). Examination of aspirin-induced gastric ulcer group (II) revealed dense irregularly arranged collagen fibers in the lamina propria at the base of the ulcer between the distorted fundic glands (Figure 9b).

In gastric ulcer group treated with trio-clar (IIIa), denser collagen fibers than the control could be detected in the lamina propria between the reconstructed fundic glands (Figure 9c). Gastric ulcer group treated with purslane extract (IIIb), revealed nearly normal fine collagen fibers in the lamina propria in between reconstructed fundic glands, and around congested blood vessels in the submucosa as compared to the control group (Figure 9d). Collagen fibers distribution in the lamina propria and the submucosa of the fennel extract-treated group (IIIc) was denser than the control (Figure 9e). Finally, Masson's trichrome stained section of the gastric ulcer group with a combination of both purslane and fennel extracts (IIId) was broadly similar to the control (Figure 9f).

\section{Toluidine blue-stained sections results}

No mast cells could be detected in the lamina propria of the fundic glands or the submucosa in the control group (Figure 10a). While high infiltration of mast cells in the gastric mucosa and in the submucosal regions was detected in the aspirin-induced gastric ulcer group (II) (Figure 10b). However, the infiltration of mast cells was considerably suppressed in the gastric ulcer groups treated with either trio-clar (IIIa), purslane (IIIb), fennel (IIIc) with marked improvement in the combined purslane \& fennel extracts treated group (IIId) as compared to the control group (Figures 10c-10f) respectively.

\section{Electron microscopic results}

Examination of ultrathin sections of the glandular gastric mucosa of the control group showed mucus neck cell with euchromatic nucleus. The cytoplasm depicted well developed Golgi complex formed of flattened saccules and vesicles, mitochondria with prominent cristae and apical electron-dense mucous granules (Figure 11a). The pyramidal parietal cell had rounded euchromatic nucleus. The cytoplasm revealed deep intracellular canaliculi lined with numerous finger-like microvilli, many round to ovoid mitochondria with prominent cristae and sparse of rough endoplasmic reticulum (Figure 11b). The columnar chief cell contained oval euchromatic nucleus with peripheral heterochromatin on the inner aspect of the nuclear envelope. The cytoplasm depicted closely packed cisternae of rough endoplasmic reticulum and multiple variablesized electron dens zymogen granules (Figure 11c).

Meanwhile, ultrathin sections examination of aspirininduced gastric ulcer group (II) revealed severely damaged mucus neck cells with a distorted apical part, the nucleus was atypical with irregular outline and chromatin margination. Many vacuoles appeared in the cytoplasm (Figure 12a). The parietal cell appeared distorted with dilated perinuclear cisternae, dilated tubulovesicular system with disrupted microvilli lined the widely dilated intracellular canaliculi and dilated Golgi complex, increased density of the mitochondrial matrix (Figure 12b). The chief cells depicted shrunken irregular electron-dense nuclei with dilated perinuclear cisternae, markedly dilated rough endoplasmic reticulum, dilated Golgi complex in tubular and vesicular forms and many electron-lucent to moderate electron-dense zymogen granules (Figure 12c).

Ultrathin sections from the gastric ulcer group treated with trio-clar (IIIa), showed mucus neck cell with dilated perinuclear cisternae of the irregular nucleus. The cell revealed apical electron-dense mucus granules and dilated Golgi apparatus (Figure 13a). The parietal cell heterochromatic nucleus with prominent nucleoli and slightly dilated perinuclear cisternae, increased tubulovesicular system and many round to ovoid electrondense mitochondria obscured cristea (Figure 13b). Peptic cell had a large irregular nucleus, numerous moderate variable-sized electron-dense zymogen granules and slightly dilated rough endoplasmic reticulum (Figure 13c).

Ultrathin section from the gastric ulcer group treated with purslane extract (IIIb), showed mucus neck cell 
with euchromatic nucleus, numerous apical electrondense mucus granules and dilated Golgi complex (Figure 14a). The parietal cell revealed dilated perinuclear cisternae, of the euochromatic nucleus, many round to ovoid mitochondria with prominent cristea (Figure 14b). The peptic cell had large indented nucleus with slightly dilated perinuclear cisternae, many variable sized zymogen granules appeared coalesced filling the entire cell (Figure 14c).

Examination of ultrathin sections of the glandular gastric mucosa of the ulcer group treated with fennel extract (IIIc), showed mucus neck cell with slightly dilated perinuclear cisternae of an euchromatic nucleus. The apical cytoplasm depicted numerous electron-dense mucus granules and many vacuoles appeared at the basal part of the cell (Figure 15a). The parietal cell revealed dilated perinuclear cisternae of the euchromatic nucleus. Normal intracellular canaliculi lined with microvilli and many electron-dense mitochondria obscured cristea (Figure 15b). Peptic cell with a shrunken irregular electron-dense heterochromatic nucleus, numerous variable-sized electron-dense zymogen granules with few cytoplasmic vacuolations in-between. Enteroendocrine cells appeared with distorted granules and cytoplasmic vacuolations (Figure 15c).

Finally, the examination of the ultrathin sections from gastric ulcer group treated with combined purslane and fennel extracts (IIId), showed apparently normal mucus neck cell with euchromatic nucleus and prominent nucleolus, numerous apical electron-dense mucinogen granules, closely packed cisternae of rough endoplasmic reticulum and scattered mitochondria (Figure 16a). Apparent improved parietal cell with euchromatic nucleus, normal mitochondria with prominent cristea and secondary lysosomes (Figure 16b). Normal peptic cells with euchromatic nucleus, many moderate electron-dense variable-sized zymogen granules filling the entire cell and normal closely packed cisternae of rough endoplasmic reticulum (Figure 16c).

\section{Statistical and morphometric results}

As regarding the histomorphometric analysis, it was found that the statistical comparison between control subgroups (IA, IB) revealed no significant difference among them $(p>0.05)$; therefore, all comparisons were referred to the control group.

The mean values of initial body weight among rats of all experimental groups were nearly similar with no statistically significant difference $(P>0.05)$. At the end of the experiment, the least recorded mean of the final body weight was among the aspirin-induced gastric ulcer group (II). While the highest mean value was recorded among fennel extract-treated group (IIIc) followed by the combined purslane and fennel extracts (IIId), purslane extract (IIIb) and trio-clar (IIIa) treated groups respectively, on comparison to the aspirin administrated group. However, improvement in the bodyweight could not reach to the control values as there was a significant difference when compared to the control group. All these values were of statistically significant difference $(P<0.05)$ (Table 1).

The mean number of parietal cell among all rats of the experimental groups was illustrated in the (Table 2 and Histogram 1). The least recorded mean value was among the aspirin-induced gastric ulcer group (II), followed by trio-clar treated group (IIIa) as compared to the control rats. While the highest mean value was among the combined purslane and fennel extracts treated rats (GIIId) followed by purslane extract (GIIIb) and finally, fennel extract (GIIIc) treated groups respectively on comparison to the aspirin administrated group with a statistically significant difference.

Statistical analysis of the mean area \% of collagen revealed that aspirin administrated group (II) recorded the highest mean value when compared to the control group $(P<0.05)$. Improvement was detected among treated groups, with the least value was among the combined purslane and fennel extracts treated rats (IIId), followed by purslane (IIIb), fennel (IIIc) and trio-clar (IIIa) treated groups respectively on comparable to the aspirin-induced gastric ulcer group (II) with statistically significant difference (Table 3 and Histograms 2). However, the reduction in the area $\%$ of collagen among the treated groups could not reach to the control values as there was a significant difference when compared to the control subgroups $(P<0.05)$.

Statistical analysis of the mean number of mast cells among the experimental groups showed that the highest mean value was among aspirin administrated group (II) when compared to the control subgroups $(P<0.05)$. Improvement was detected among treated groups, with the least value was among the combined purslane and fennel extracts treated rats (IIId), followed by fennel (IIIc), purslane (IIIb) and finally trio-clar (IIIa) groups respectively on comparable to the aspirin administrated group (II) with statistically significant difference (Table 4 and Histograms 3). However, the reduction in the mast cell count could not reach to the control values as there was a significant difference when compared to the control group $(P<0.05)$. 


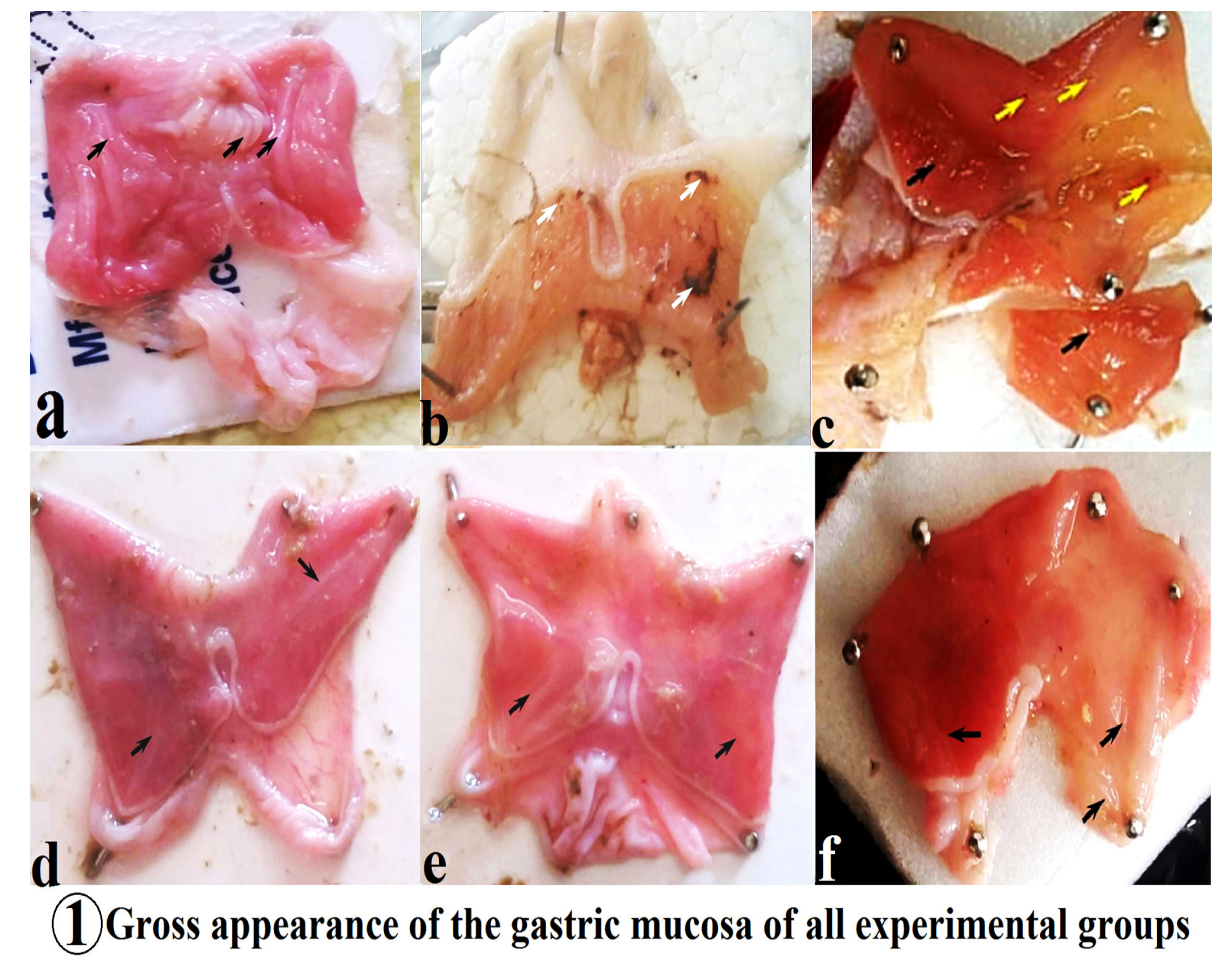

Fig. 1: Gross examination of the gastric mucosa of all experimental groups showing: (a) control group has normal pink colouration with prominent rugae (black arrows).(b) Aspirin-induced gastric ulcer group (II), showing: brownish hemorrhagic spots and streaks (white arrows) among the pale gastric mucosa. (c) Trio-clar treated group (IIIa), small tiny hyperemic spots (yellow arrows)among the most normal gastric mucosa(black arrows) is noticed. (d,e,f) gastric ulcer groups treated with purslane (IIIb), fennel (IIIc) and with combined purslane \& fennel extracts (IIId) respectively showing: apparent normal pink gastric mucosa with prominent rugae (black arrows)more or less as the control.

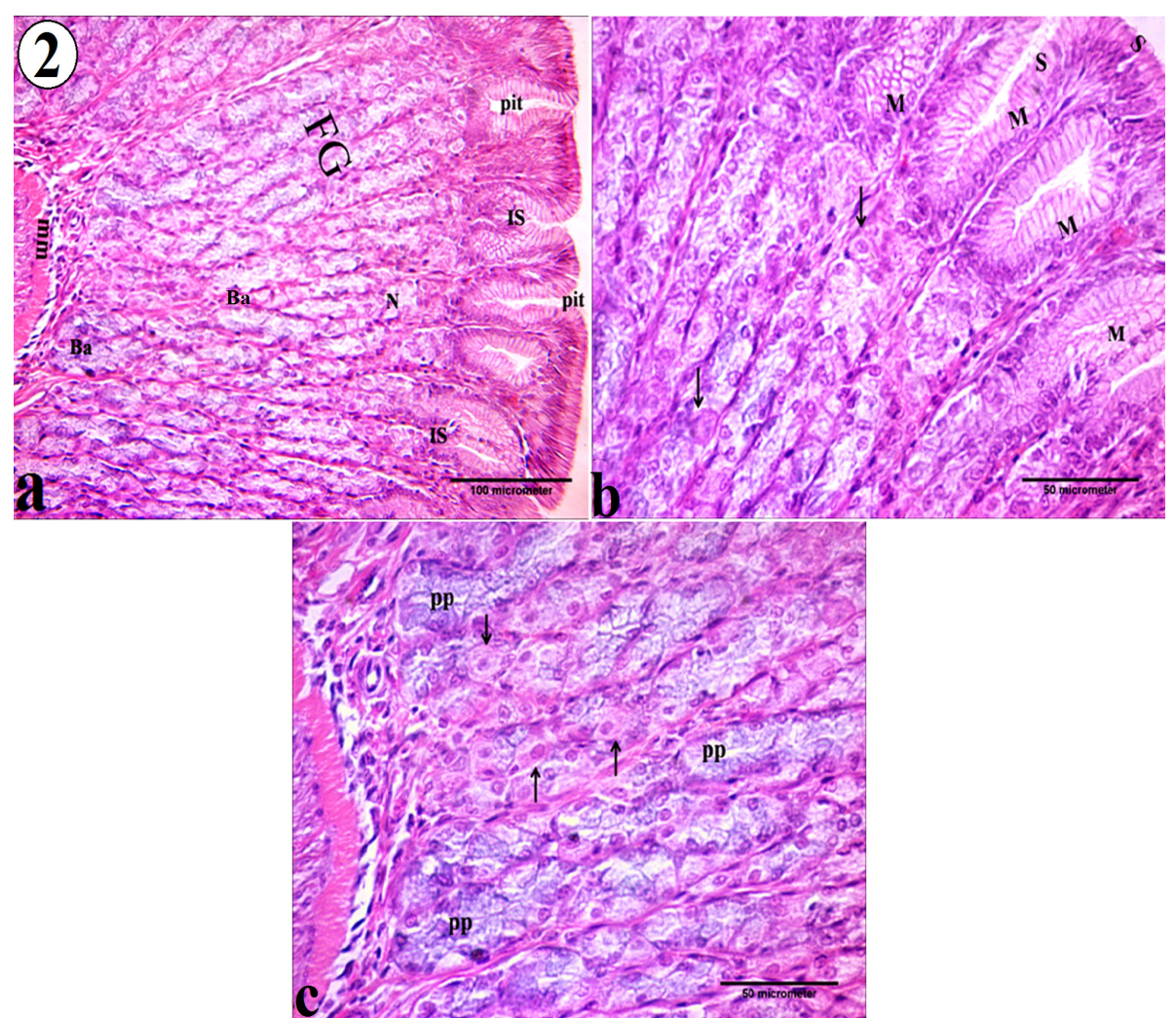

Fig. 2: photomicrographs of the fundic mucosa from the control group showing: (a) Closely packed tubular fundic glands (FG), gastric pits (arrows) and muscularis mucosa (mm). Fundic glands are composed of isthmus (Is), neck (N) and base (Ba). (b) Surface columnar epithelium (S) with pale apical cytoplasm and basal oval nuclei, mucous neck cell (M) with foamy cytoplasm and basal flattened nuclei line the apical part of fundic glands. Parietal cells (arrows) are also noticed. (c) Pyramidal parietal cells (arrows) with deep acidophilic cytoplasm and central rounded vesicular nuclei as well as low columnar peptic cells (pp) with basophilic cytoplasm and basal rounded nuclei line the body and base regions of fundic glands. (H\&E; (a) x 200, scale bar=100 $\mu \mathrm{m} \&$ (b,c) x 400, scale bar $=50 \mu \mathrm{m}$ ) 


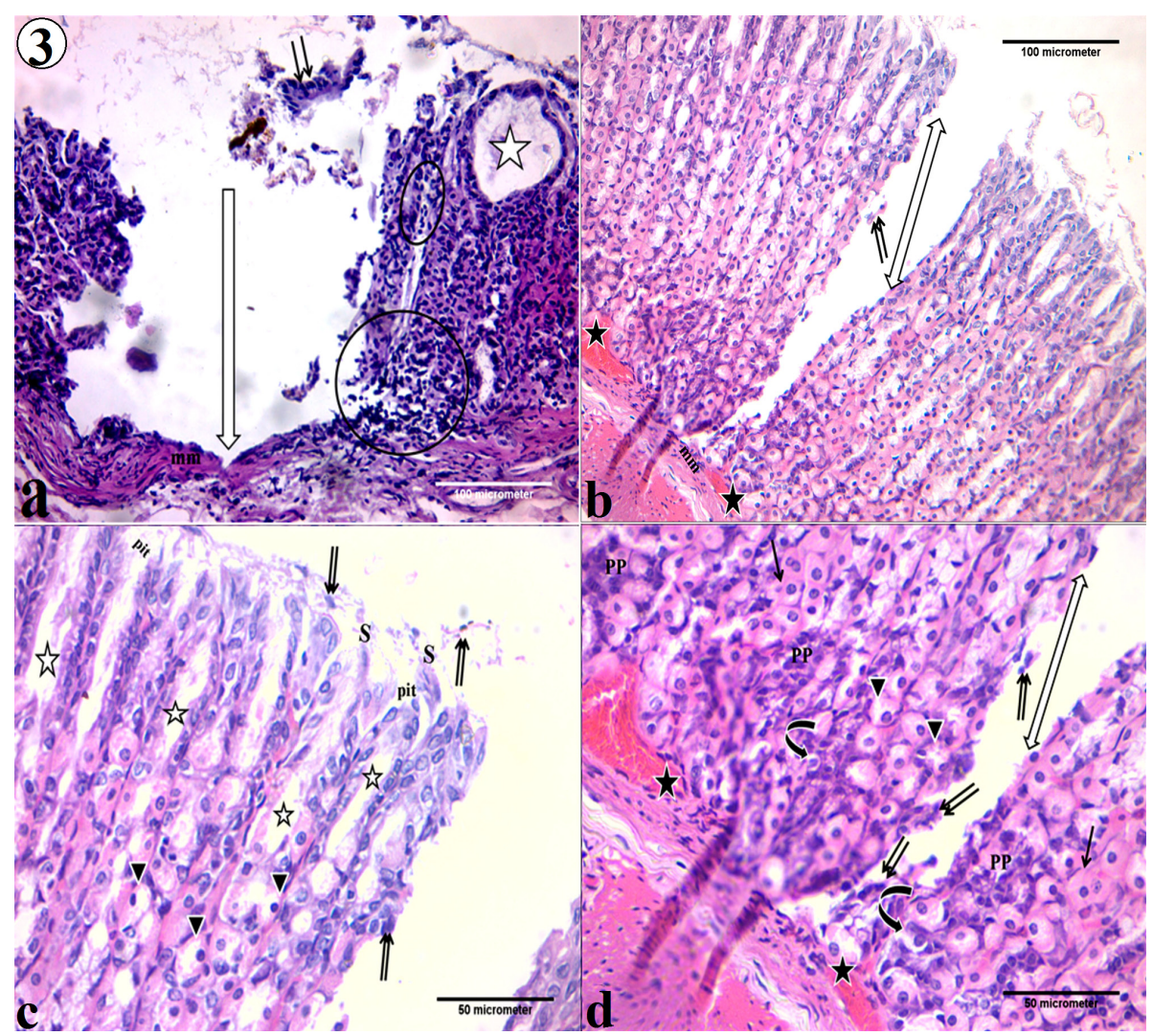

Fig. 3: photomicrographs of the fundic mucosa from the aspirin-induced gastric ulcer group (II), showing: (a) Deep gastric ulcer (white arrow) extends down to muscularis mucosa ( $\mathrm{mm}$ ), wide distorted fundic glands (white star) with desquamated cells remnants in the lumen (double arrows).Inflammatory cell infiltrations (circle) in the lamina propria near the ulcerated region can be seen. (b) Exfoliation of the lining cells (double arrow) in between gastric ulcer (double-headed arrow) and blood vessels congestion (black star) in the lamina propria near the basal parts of the fundic glands. (c) Wide pits and fundic glands (white star), sloughing surface lining cells (S) have deep acidophilic cytoplasm with darkly stained nuclei (double arrows). Parietal cells (arrowheads) are vacuolated with darkly stained small nuclei. (d) Deeply stained desquamated cells (double arrows), wide edged gastric ulcer (double-headed arrow).Parietal cells (arrowheads) are vacuolated, others with acidophilic cytoplasm (arrows). Deeply stained peptic cells (pp), as well as vacuolated chief cells (curved arrows) with darkly stained nuclei, are evident at the basal part of the fundic gland.Notice, congested blood vessels (black star) in the lamina propria near the basal parts of the fundic glands. (H\&E; (a,b) x 200, scale bar $=100 \mu \mathrm{m} \&(\mathrm{c}, \mathrm{d}) \times 400$, scale bar=50 $\mu \mathrm{m}$ )
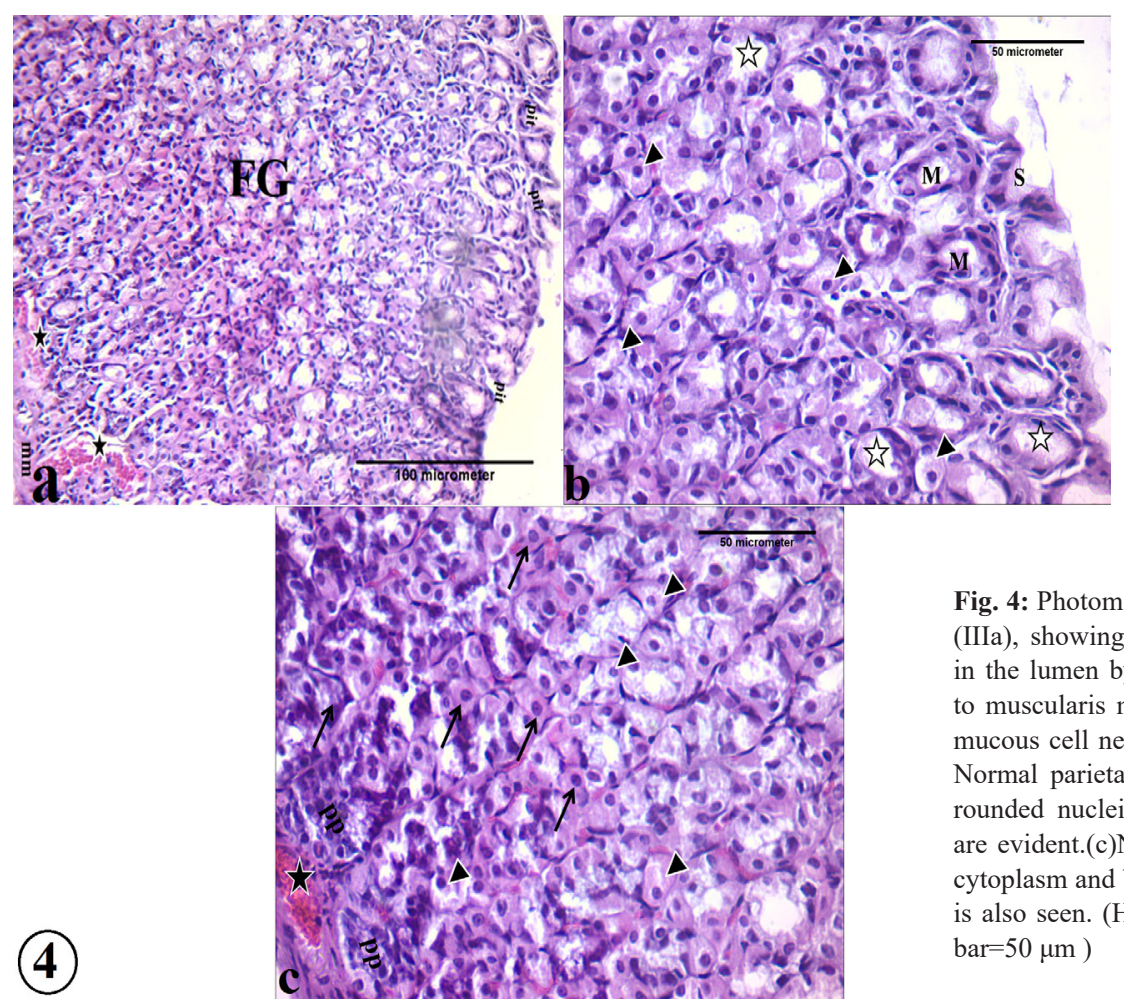

Fig. 4: Photomicrographs of the gastric ulcer group treated with trio-clar (IIIa), showing: (a) A near-normal closely packed fundic glands open in the lumen by gastric pits. Congested blood vessels (black star) near to muscularis mucosa $(\mathrm{mm})$ are evident. (b) Surface mucous cells $(\mathrm{S})$, mucous cell neck cell (M) are nearly similar to the control group. (b,c) Normal parietal cells (arrows) with acidophilic cytoplasm and central rounded nuclei as well as few vacuolated parietal cells (arrowheads) are evident.(c)Numerous normal peptic cells (PP) with deep basophilic cytoplasm and basal rounded nuclei. Congested blood vessel (black star) is also seen. (H\&E; (a) x 200, scale bar $=100 \mu \mathrm{m} \&(\mathrm{~b}, \mathrm{c})$ x 400 , scale bar $=50 \mu \mathrm{m}$ ) 

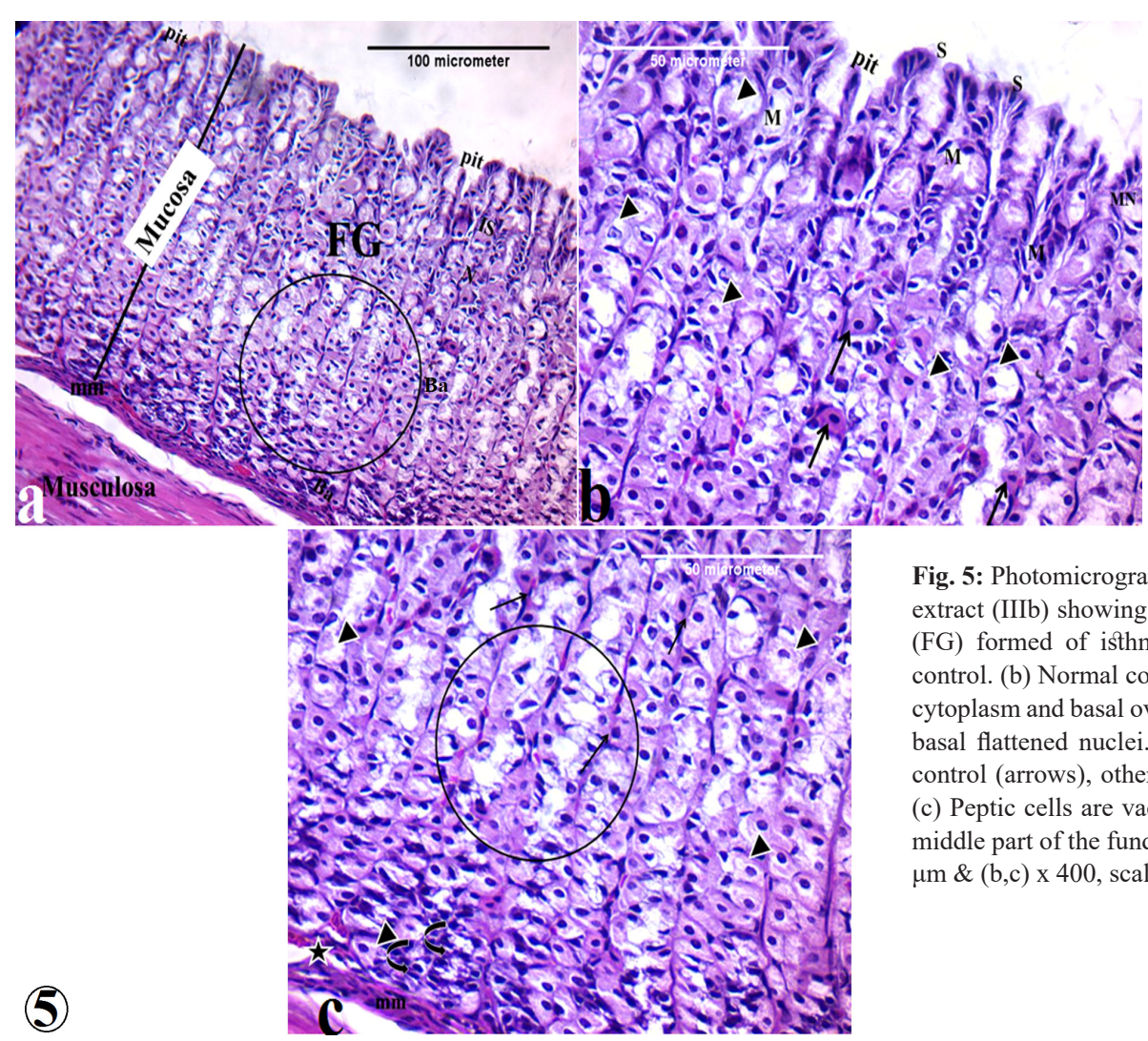

Fig. 5: Photomicrographs of the gastric ulcer group treated with purslane extract (IIIb) showing: (a) Closely packed regular straight fundic glands (FG) formed of isthmus (Is), neck (N), and base (Ba) nearly as the control. (b) Normal columnar surface epithelial cells (S) with acidophilic cytoplasm and basal oval nuclei, low columnar mucus neck cells (M) with basal flattened nuclei. (b,c) Parietal cells appear closely similar to the control (arrows), others appear with vacuolated cytoplasm (arrowhead). (c) Peptic cells are vacuolated (curved arrows). Notice, dilatation of the middle part of the fundic glands (circle). (H\&E; (a) x 200, scale bar=100 $\mu \mathrm{m} \&(\mathrm{~b}, \mathrm{c}) \times 400$, scale bar $=50 \mu \mathrm{m})$
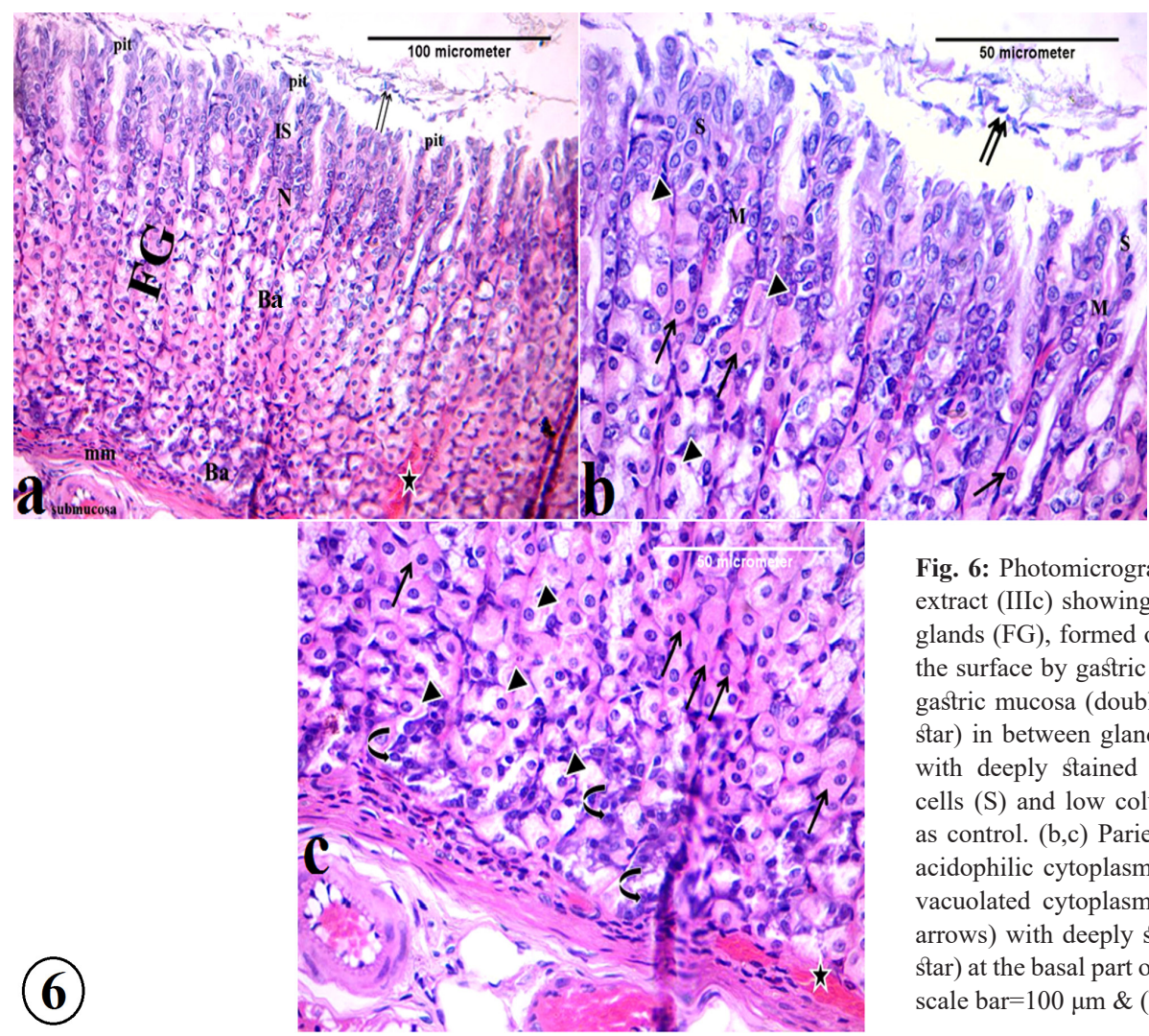

Fig. 6: Photomicrographs of the gastric ulcer group treated with fennel extract (IIIc) showing: (a) normal glandular architecture of the fundic glands (FG), formed of isthmus (Is), neck (N), and base (Ba) opened on the surface by gastric pits, desquamated epithelial cells overly the intact gastric mucosa (double arrows). Notice, congested blood vessels (black star) in between glands.(b) Deeply stained desquamated epithelial cells with deeply stained nuclei (double arrow), columnar surface mucus cells (S) and low columnar mucus neck cells (M) appear more or less as control. (b,c) Parietal cells appear nearly normal(arrows)with highly acidophilic cytoplasm and central rounded nucleus. Others appear with vacuolated cytoplasm (arrowhead).(c) Vacuolated peptic cells (curved arrows) with deeply stained nuclei and blood vessels congestion (black star) at the basal part of fundic glands are also observed. (H\&E; (a) x 200, 


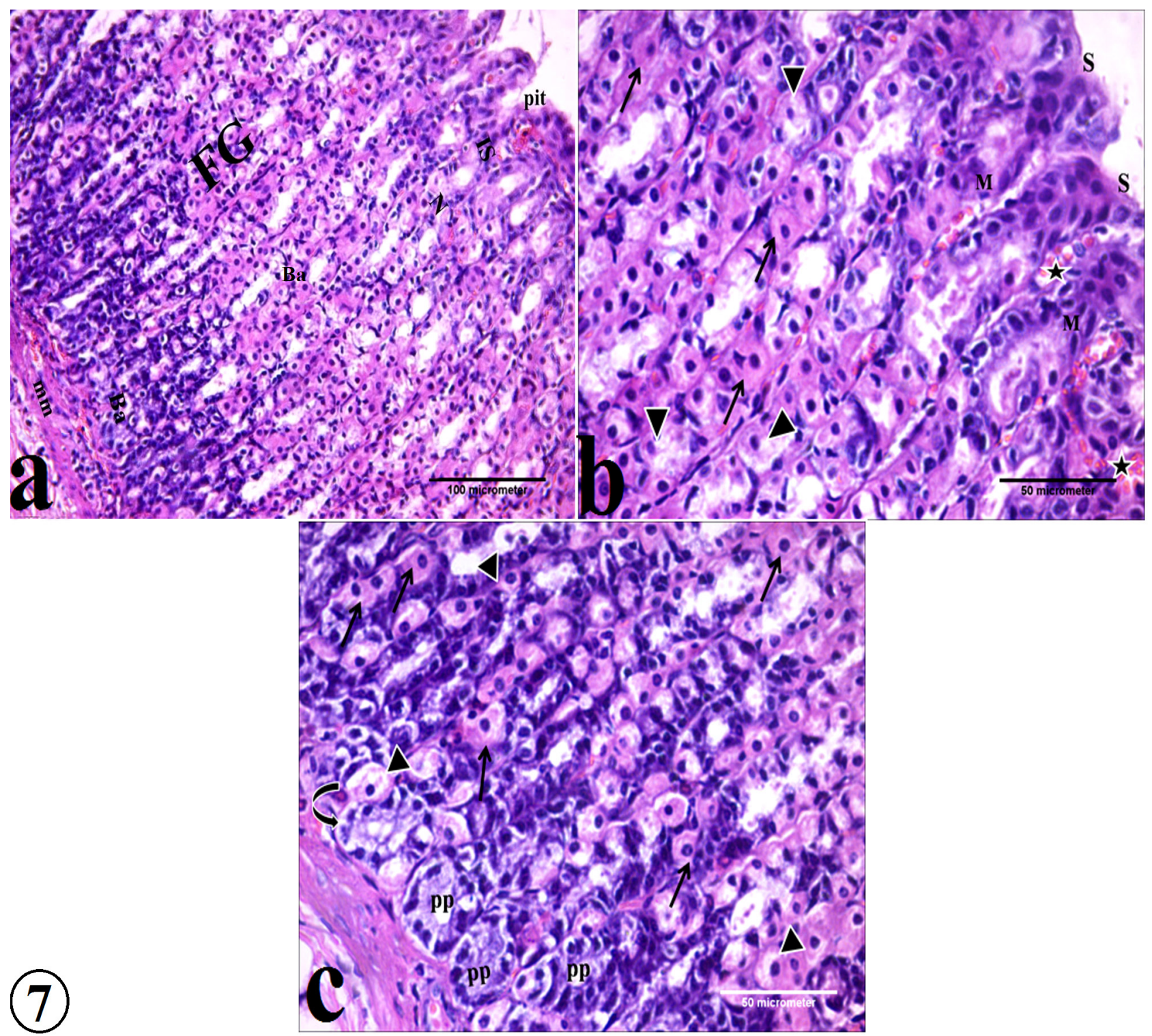

Fig. 7: photomicrographs of the gastric ulcer group treated with combination of both purslane and fennel extracts (IIId) showing: (a) Normal fundic glands (FG) open in the lumen by short narrow gastric pits (b) The surface columnar mucus-secreting cells, mucus neck cells are closely similar to the control group. $(b, c)$ Numerous normal parietal cells with highly acidophilic cytoplasm (arrows) and central rounded nuclei notice, few vacuolated parietal cells (arrowhead) and congested blood vessels (black stars) in-between intact fundic glands.(c) Numerous normal peptic cells (PP) with basophilic cytoplasm and basal rounded nuclei along with few vacuolated peptic cells (curved arrows) at the basal part of the gland. (H\&E; (a) x 200, scale bar=100 $\mu \mathrm{m} \&(\mathrm{~b}, \mathrm{c})$ x 400, scale bar=50 $\mu \mathrm{m}$ ) 


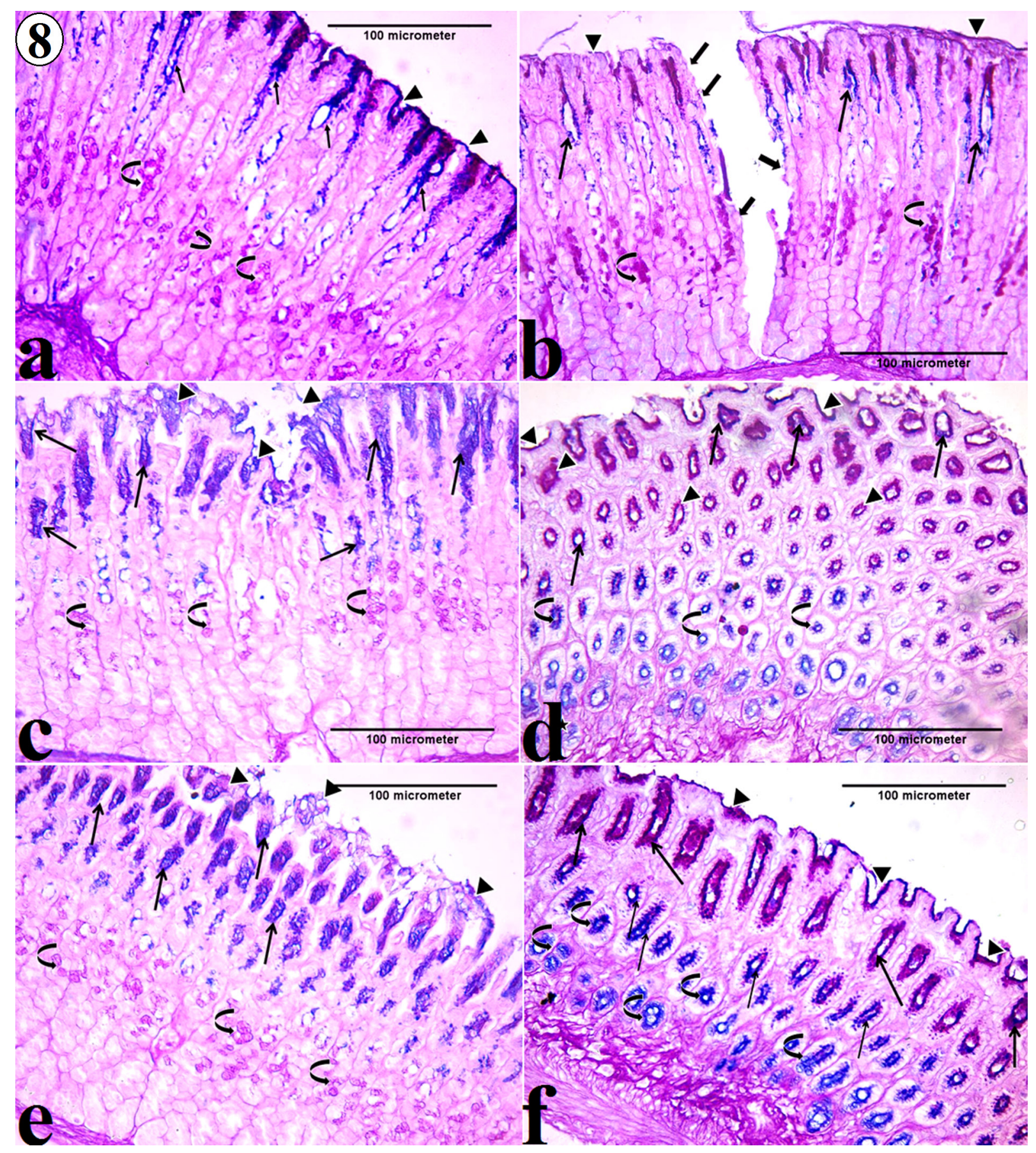

Fig. 8: Photomicrographs of the gastric mucosa of all experimental groups showing :(a) Control group with magenta-red PAS-positive mucous film inclines the mucosal surface, pits (arrowheads) and body regions (curved arrows) of the fundic glands. Alcian blue +vereaction at the deeper part of the gastric pit, isthmus and the neck regions (arrows) is also observed.(b) Gastric ulcer group (II) reveals the absence of the reaction at the ulcerated regions (thick arrows). Notice, PAS +ve reaction within body region (curved arrows) and in the nearby intact surface epithelium (arrowhead), extends towards the ulcerated regions. Some alcian blue positive reaction in the intact nearby neck regions (thin arrows) is also observed. (c) Trio-clar treated group (IIIa) showing: nearly normal strong PAS-positive mucus film at the reconstructed surface cells, isthmus (arrowheads), the body regions (curved arrows) and +ve alcian blue reaction on the isthmus and neck regions(thin arrows). (d) Purslane extract-treated group (IIIb) showing: normal reactions more or less as the control. Notice, more prominent alcian blue +ve reaction at the basal part of the gland.(e) In fennel extract-treated group (IIIc), interrupted PAS-positive mucus film on the surface (arrowheads) and positive alcian blue reaction (thin arrows)on the neck regions are observed. (f) In gastric ulcer treated with purslane \&fennel extracts (IIId) PAS reactions(arrowheads) and alcian blue (thin arrows) reactions broadly resemble the control group (Alcian blue\& PAS; x200 , scale bar=100 $\mu \mathrm{m}$ ) 


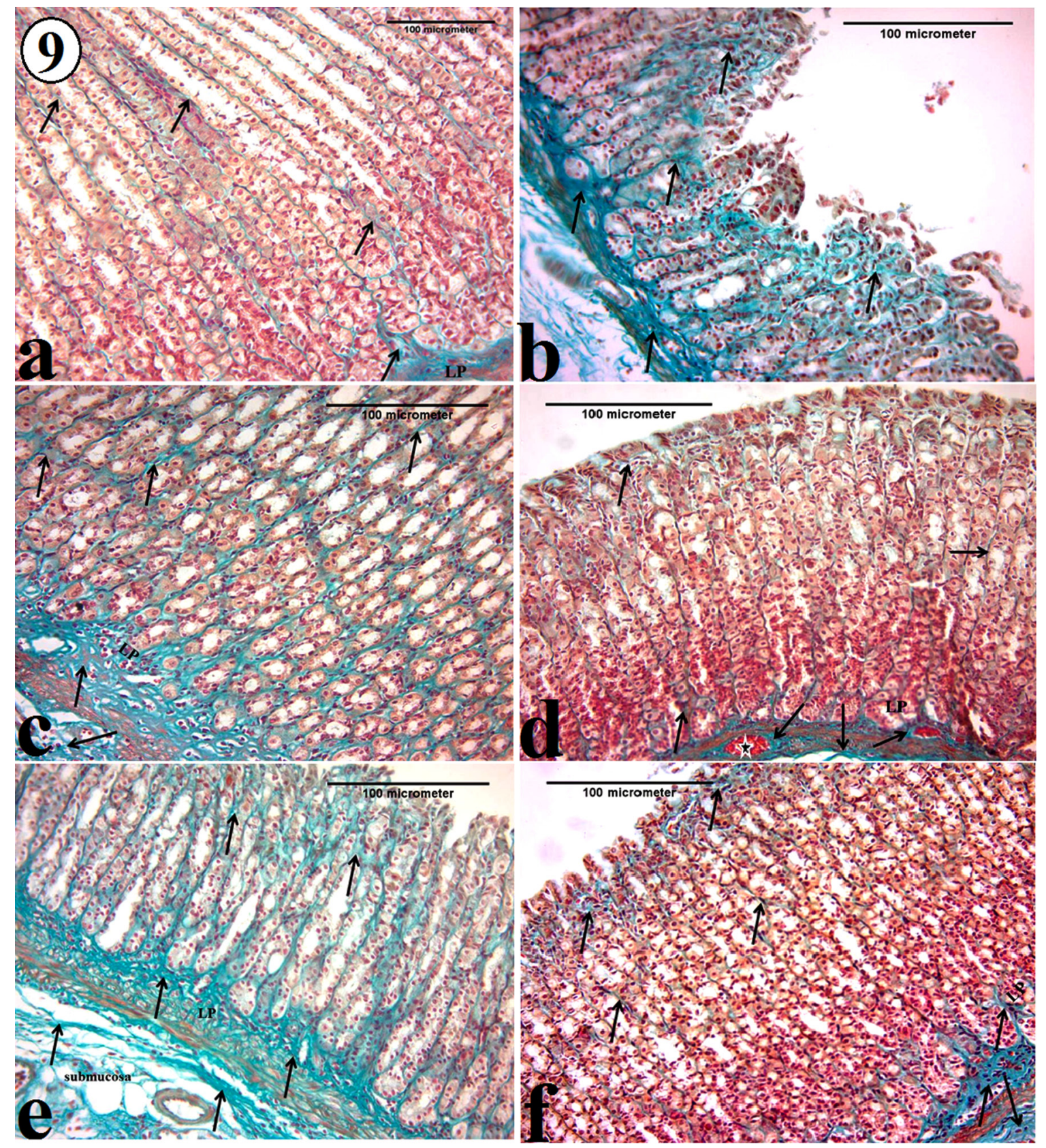

Fig. 9: Photomicrographs of the gastric mucosa of all experimental groups showing: (a) Control group with fine collagen fibers (arrows) in the lamina propria (LP) between fundic glands. (b) Gastric ulcer group (II) reveals an increase in the density and distribution of collagen fibers (arrows) in the lamina propria in between damaged fundic glands. (c)Trio-clar-treated group (IIIa) showing denser collagen fibers (arrows) in between reconstructed fundic glands and in the lamina propria (LP). (d) Purslane extract-treated group (IIIb) showing: nearly normal collagen fibers (arrows) in the lamina propria (LP) and around congested blood vessels (black star) in the submucosa as compared to the control. (e) In fennel extract-treated group (IIIc), denser collagen fibers (arrows) in between in the lamina propria (LP) and in the submucosa (arrows) than the control group. (f) Gastric ulcer group treated with purslane \&fennel extracts (IIIc) reveals fine collagen fibers (arrows) closely resemble the control group. (Masson's trichrome stain; x 200, scale bar=100 $\mu \mathrm{m}$ ) 


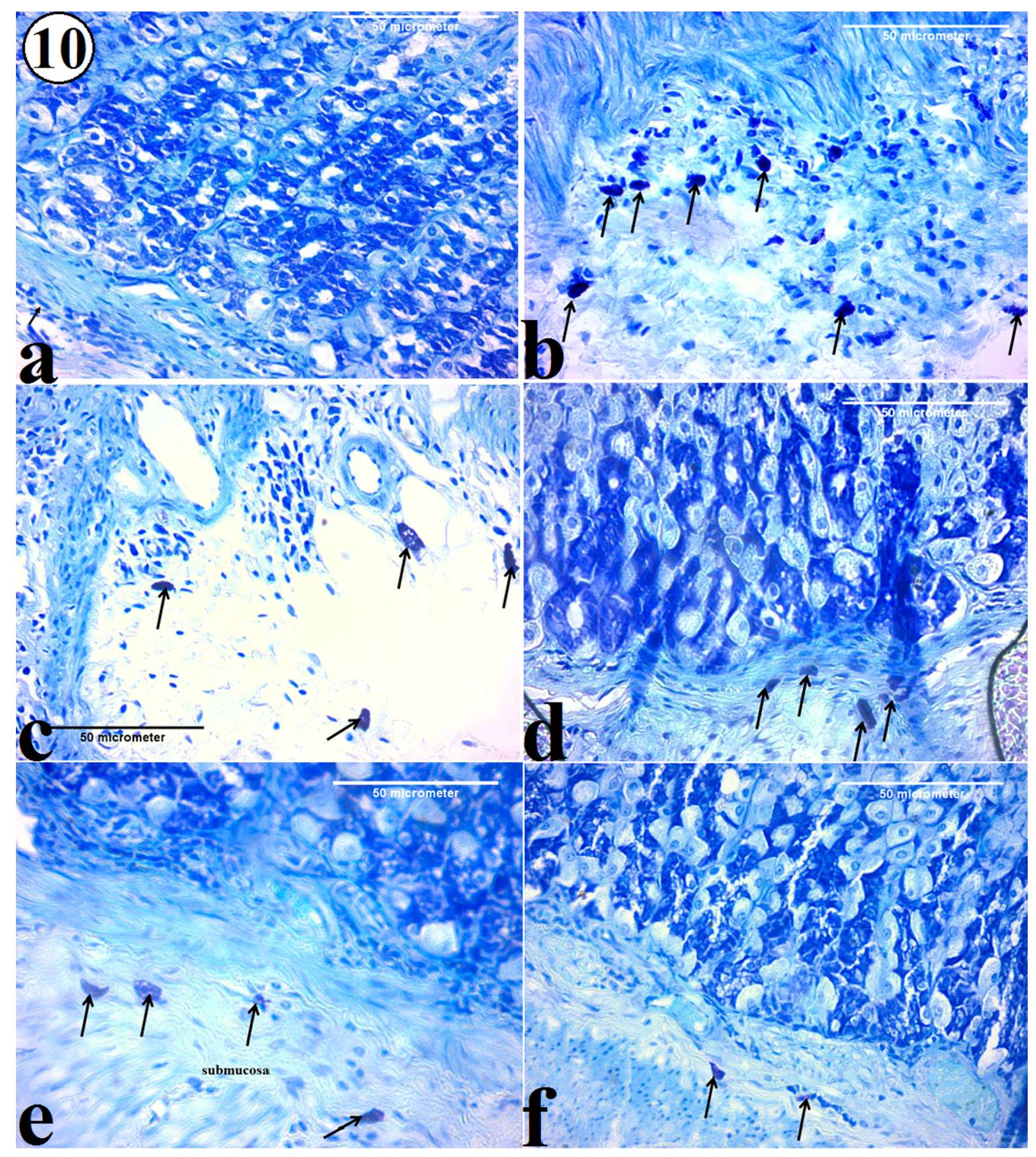

Fig. 10: photomicrographs of the gastric mucosa of all experimental groups showing :(a) No mast cells in the lamina propria of the fundic glands or the submucosa in the control group. (b) Gastric ulcer group (GII) reveals high infiltration of mast cells (arrows) in the fundic submucosa. (c,d,e,f) Gastric ulcer treated with trio-clar, purslane, fennel and the combined purslane \&fennel extracts respectively reveal marked suppression in mast cells infiltration as compared to the control group. (Toluidine blue; $\mathrm{x} 400$, scale bar $=50 \mu \mathrm{m}$ ) 

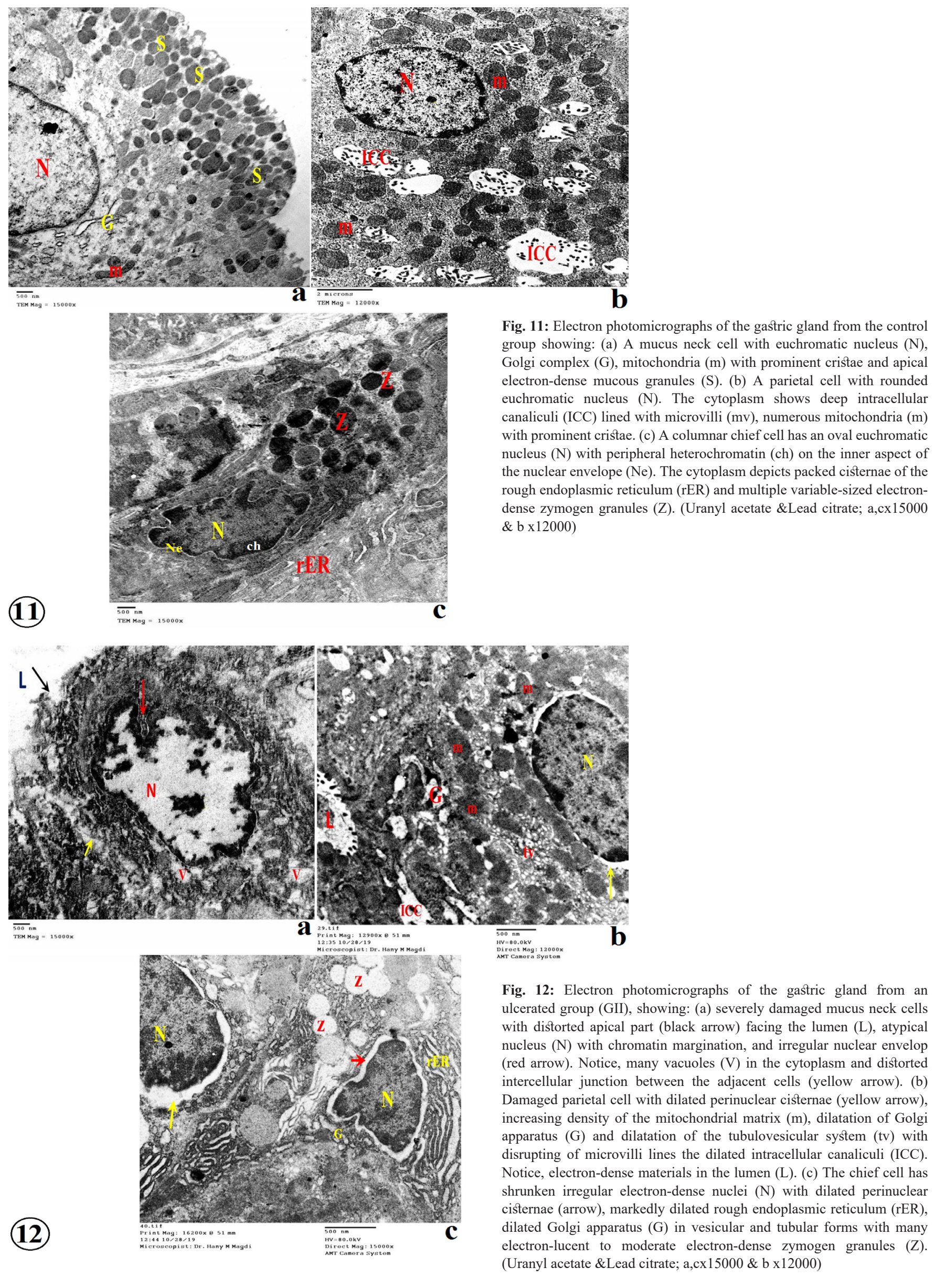


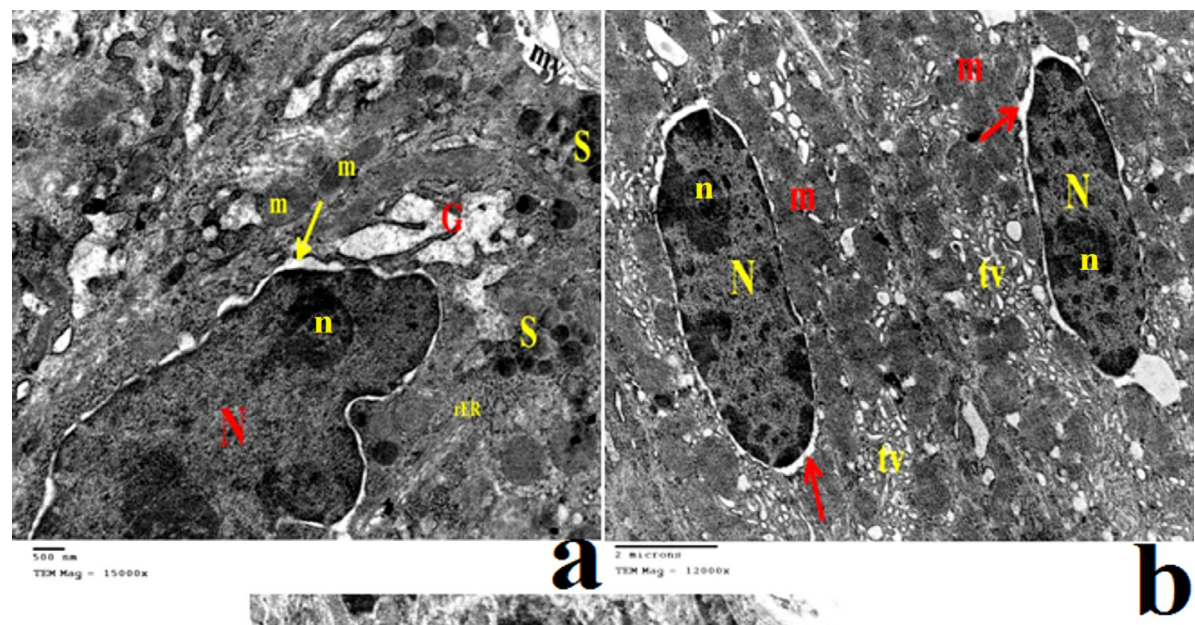

(13)

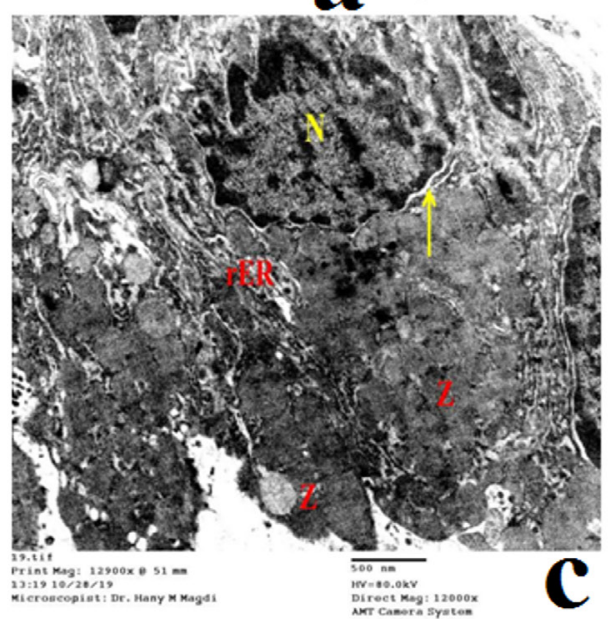

Fig. 13: Electron photomicrographs of the gastric gland from the gastric ulcer treated with Trio-clar (GIIIa), showing: (a) Mucus neck cell has a large irregular nucleus $(\mathrm{N})$ with prominent nucleoli $(\mathrm{n})$, dilated perinuclear cisternae (yellow arrow). The cell has intact apical microvilli $(\mathrm{mv})$ project into the lumen $(\mathrm{L})$ and electron-dense mucus granules $(\mathrm{S})$ Notice, severely dilated Golgi apparatus $(G)$. (b) Two parietal cells having heterochromatic nucleus $(\mathrm{N})$ with prominent nucleoli (n), slightly dilated perinuclear cisternae (red arrow), increased tubulovesicular system (tv) and many round to ovoid electron-dense mitochondria obscured cristea (m). (c) The peptic cell has large irregular nucleus $(\mathrm{N})$ with a slightly dilated nuclear envelope (arrow), variable-sized electron-dense zymogen granules ( $Z$ ) and slightly dilated rough endoplasmic reticulum (rER) (Uranyl acetate \&Lead citrate; a x15000 \& b,c x12000)
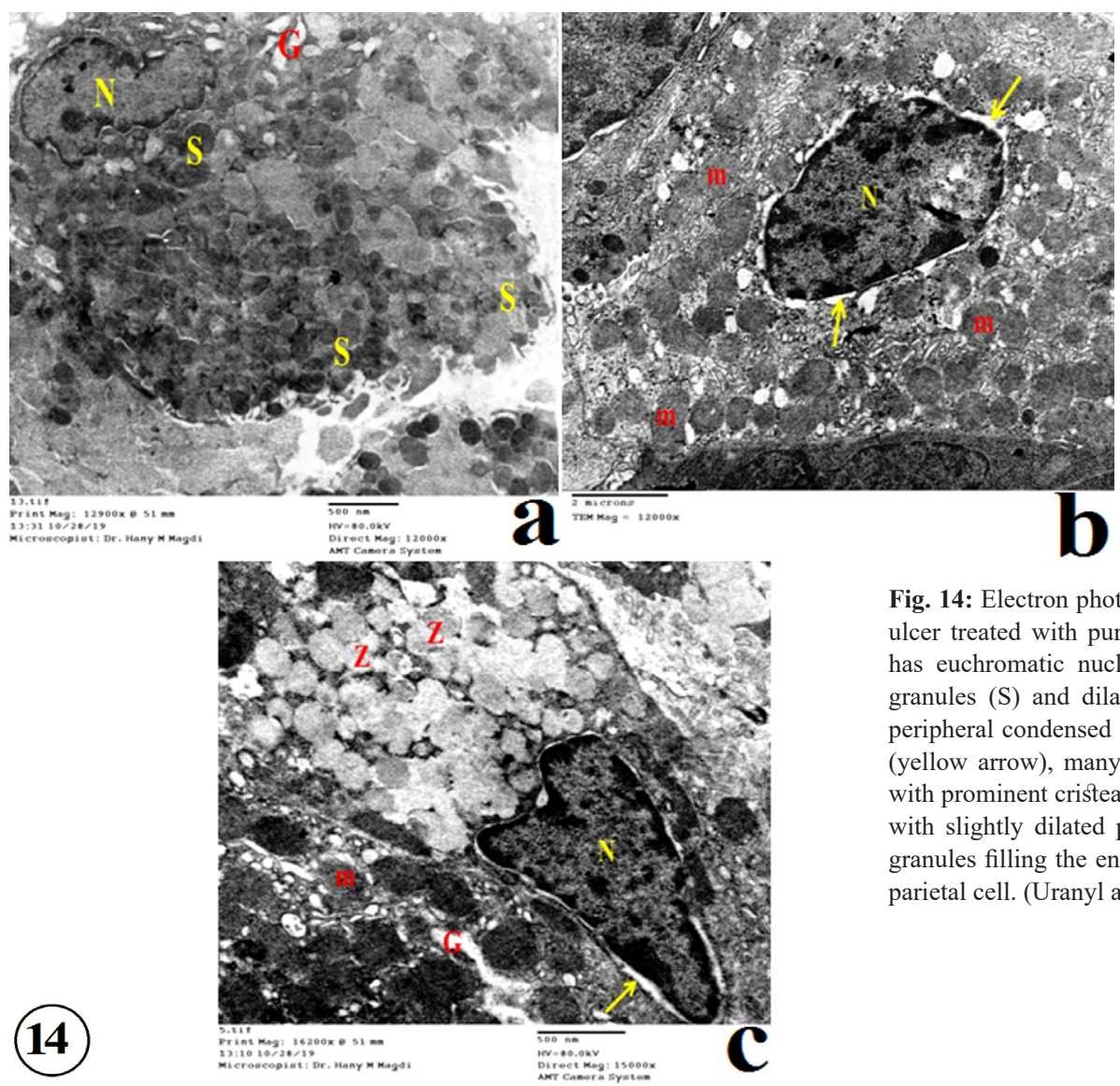

Fig. 14: Electron photomicrographs of the gastric gland from the gastric ulcer treated with purslane extract (IIIb), showing: (a)mucus neck cell has euchromatic nucleus $(\mathrm{N})$, numerous apical electron-dense mucus granules (S) and dilated Golgi complex (G).(b) The parietal cell has peripheral condensed heterochromatin with dilated perinuclear cisternae (yellow arrow), many round to ovoid electron-dense mitochondria (m) with prominent cristea. (c) The peptic cell has large indented nucleus $(\mathrm{N})$ with slightly dilated perinuclear cisternae (arrow), coalesced zymogen granules filling the entire cell. Notice, mitochondria $(\mathrm{m})$ of the adjacent parietal cell. (Uranyl acetate \&Lead citrate; a,bx12000\&c x15000) 

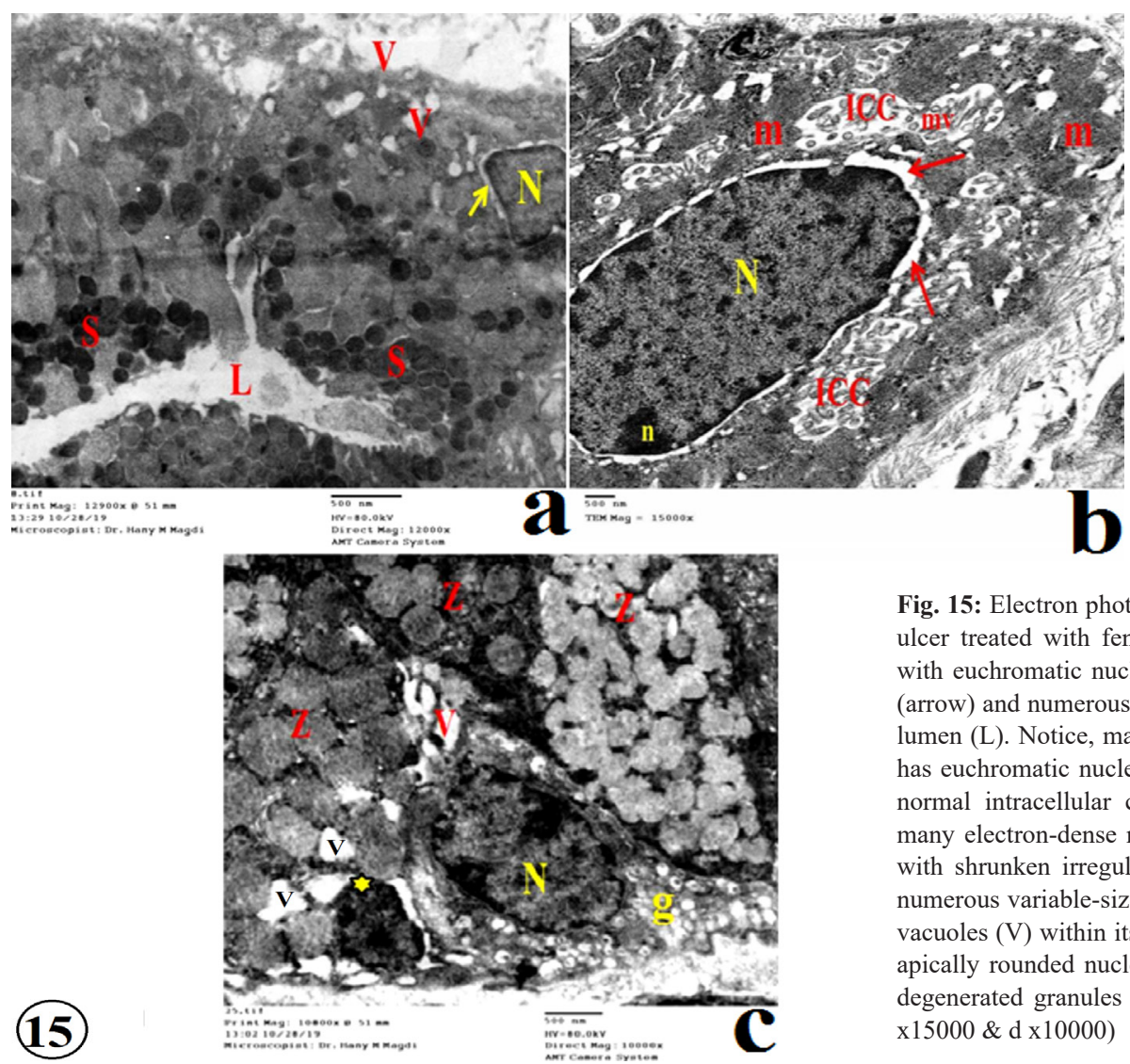

Fig. 15: Electron photomicrographs of the gastric gland from the gastric ulcer treated with fennel extract (IIIc), showing: (a) mucus neck cell with euchromatic nucleus $(\mathrm{N})$ and slightly dilated perinuclear cisternae (arrow) and numerous apical electron-dense mucus granules (S) near the lumen (L). Notice, many vacuoles (V) at the basal part .(b) Parietal cell has euchromatic nucleus $(\mathrm{N})$ with dilated perinuclear cisternae (arrow), normal intracellular canaliculi (ICC) lined with microvilli (mv) and many electron-dense mitochondria obscured cristea (m). (c) Peptic cell with shrunken irregular electron-dense heterochromatic nucleus (star), numerous variable-sized electron-dense zymogen granules $(Z)$ and some vacuoles (V) within its cytoplasm. Notice, enteroendocrine cells with an apically rounded nucleus $(\mathrm{N})$, cytoplasmic vacuolation and many basal degenerated granules (g). (Uranyl acetate \&Lead citrate; a x12000 , b

$(15)$ $\mathrm{x} 15000 \& \mathrm{~d}$ x10000)

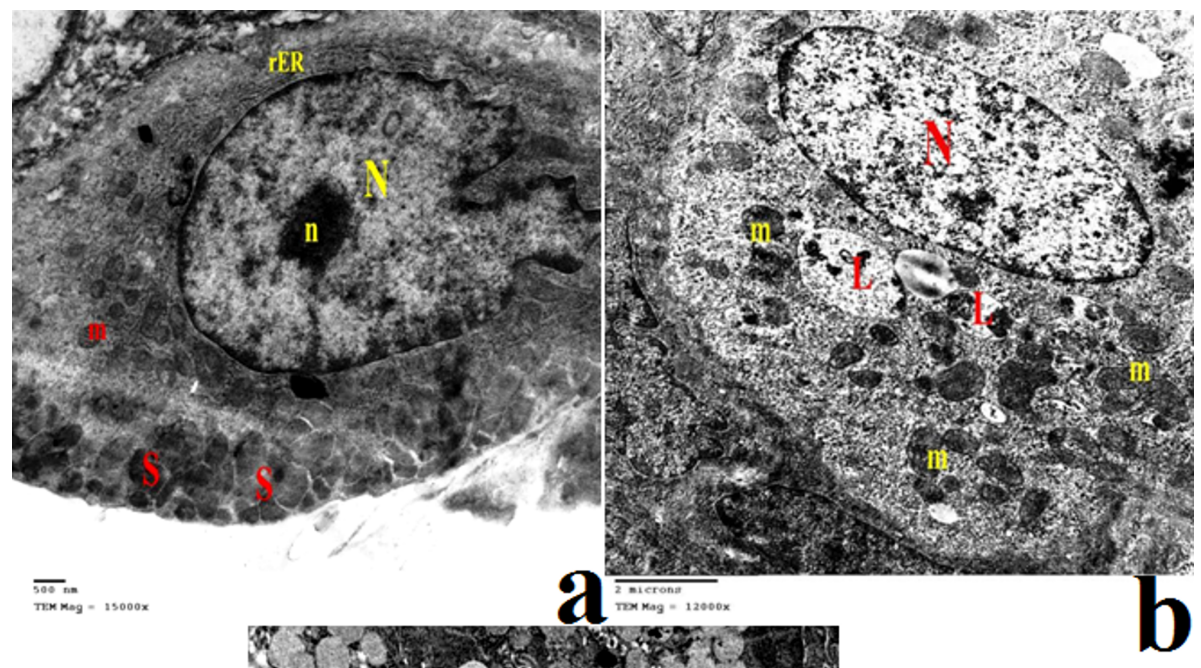

16

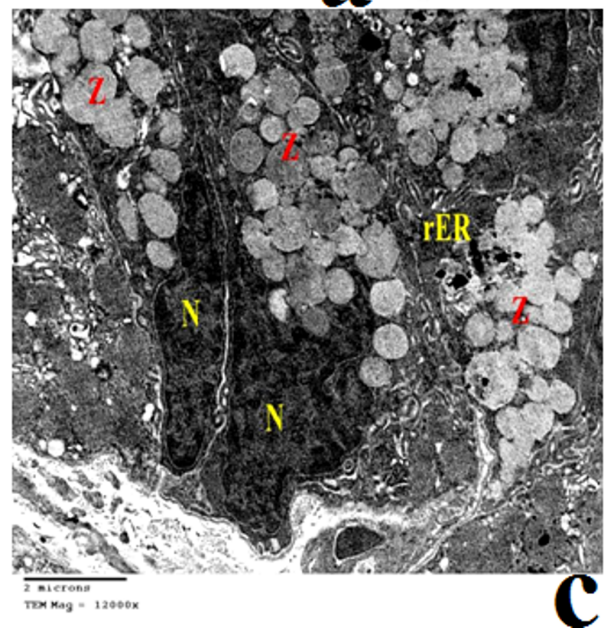

Fig. 16: Electron photomicrographs of the gastric gland from the gastric ulcer treated with combined purslane and fennel extracts (GIIId), showing: (a) normal mucus neck cell with euchromatic nucleus (N) and prominent nucleolus (n), numerous apical electron-dense mucinogen granules (S), closely packed cisternae of rough endoplasmic reticulum (rER) and scattered mitochondria (m). (b) Parietal cell with euchromatic nucleus $(\mathrm{N})$, many electron-dense mitochondria $(\mathrm{m})$ with prominen cristea . secondary lysosomes (L) is also noticed in the cytoplasm. (c) Two peptic cells with euchromatic nuclei $(\mathrm{N})$, many moderate electrondense variable sized zymogen granules ( $\mathrm{Z}$ ) filling the entire cell and normal closely packed cisternae of the rough endoplasmic reticulum. (rER). (Uranyl acetate \&Lead citrate; a x15000\& b,c x12000 ) 
Table 1: One-way ANOVA followed by Tukey's post-hoc test of the mean initial and final body weight in rats of different experimental groups

\begin{tabular}{|c|c|c|c|c|c|c|}
\hline parameters & $\begin{array}{c}\mathrm{GI} \\
\mathrm{N}=6\end{array}$ & $\begin{array}{c}\mathrm{GII} \\
\mathrm{N}=6\end{array}$ & $\begin{array}{l}\text { GIII a } \\
\mathrm{N}=6\end{array}$ & $\begin{array}{c}\text { GIII } b \\
\mathrm{~N}=6\end{array}$ & $\begin{array}{c}\text { GIII c } \\
\mathrm{N}=6\end{array}$ & $\begin{array}{c}\text { GIII d } \\
\mathrm{N}=6\end{array}$ \\
\hline $\begin{array}{l}\text { Initial body weight } \\
\qquad(\mathrm{g} \pm \mathrm{SD})\end{array}$ & $150 \pm 89$ & $148.3 \pm 7.5$ & $146.7 \pm 8.2$ & $148.3 \pm 7.5$ & $151.7 \pm 9.8$ & $146.6 \pm 8.2$ \\
\hline $\begin{array}{l}\text { Final body weight } \\
\qquad(\mathrm{g} \pm \mathrm{SD})\end{array}$ & $206.6 \pm 20.6$ & $151.6 \pm 7.5^{\Delta}$ & $165 \pm 15.16$ & $178.3 \pm 7.5^{\square}$ & $203.3 \pm 15^{\text {• }}$ & $190 \pm 10.9$ \\
\hline
\end{tabular}

SD: standard deviation; N: number of animals

$\Delta$ A significant decrease compared with all other groups.

- A significant increase compared with aspirin-induced ulcer group (GII)

$\square$ A significant decrease compared with control group (GI)

Table 2: One-way ANOVA followed by Tukey's post-hoc test of the mean number of parietal cells / high power field in rats of different experimental groups

\begin{tabular}{|c|c|c|c|c|c|c|}
\hline parameters & $\begin{array}{c}\mathrm{GI} \\
\mathrm{N}=6\end{array}$ & $\begin{array}{c}\text { GII } \\
\mathrm{N}=6\end{array}$ & $\begin{array}{l}\text { GIII a } \\
\mathrm{N}=6\end{array}$ & $\begin{array}{l}\text { GIII b } \\
\mathrm{N}=6\end{array}$ & $\begin{array}{c}\text { GIII c } \\
\mathrm{N}=6\end{array}$ & $\begin{array}{l}\text { GIII d } \\
\mathrm{N}=6\end{array}$ \\
\hline $\begin{array}{c}\text { No. of parietal } \\
\text { cells/HPF } \\
\pm \text { SD }\end{array}$ & $67.3 \pm 9.7$ & $31.4 \pm 5.1^{\wedge}$ & $39.5 \pm 1.87^{\Perp}$ & $60.5 \pm 5.1^{\prime}$ & $58.5 \pm 3.9$ & $71.3 \pm 5.31^{\bullet}$ \\
\hline
\end{tabular}

SD: standard deviation; $\mathrm{N}$ : number of animals

A A significant decrease compared with all other groups.

- A significant increase compared with aspirin-induced ulcer group (GII) and trio-clar treated group (GIIIa).

Table 3: One-way ANOVA followed by Tukey's post-hoc test of the mean values of the area percentage of collagen fibers in rats of different experimental groups

\begin{tabular}{|c|c|c|c|c|c|c|}
\hline parameters & $\begin{array}{c}\mathrm{GI} \\
\mathrm{N}=6\end{array}$ & $\begin{array}{c}\mathrm{GII} \\
\mathrm{N}=6\end{array}$ & $\begin{array}{c}\mathrm{GIII} a \\
\mathrm{~N}=6\end{array}$ & $\begin{array}{c}\text { GIII b } \\
\mathrm{N}=6\end{array}$ & $\begin{array}{c}\mathrm{GIII} c \\
\mathrm{~N}=6\end{array}$ & $\begin{array}{c}\text { GIII d } \\
N=6\end{array}$ \\
\hline $\begin{array}{l}\text { Area } \% \text { of collagen } \\
\text { fibers } \pm S D\end{array}$ & $2.3 \pm 1.1$ & $7.9 \pm 1.6^{\Delta}$ & $5.4 \pm 0.9^{\mathbf{a}}$ & $4 \pm 0.8^{\bullet \circ}$ & $4.6 \pm 1.6^{ \pm \circ}$ & $3 \pm 0.9$ \\
\hline
\end{tabular}

SD: standard deviation; N: number of animals

A A significant increase compared with all other groups.

- A significant decrease compared with aspirin-induced ulcer group (GII)

- A significant increase compared with control group (GI).

Table 4: One-way ANOVA followed by Tukey's post-hoc test of the mean number of mast cells / high power field in rats of the different experimental groups

\begin{tabular}{|c|c|c|c|c|c|c|}
\hline parameters & $\begin{array}{c}\mathrm{GI} \\
\mathrm{N}=6\end{array}$ & $\begin{array}{c}\mathrm{GII} \\
\mathrm{N}=6\end{array}$ & $\begin{array}{l}\text { GIII a } \\
\mathrm{N}=6\end{array}$ & $\begin{array}{c}\text { GIII } b \\
\mathrm{~N}=6\end{array}$ & $\begin{array}{l}\text { GIII c } \\
\mathrm{N}=6\end{array}$ & $\begin{array}{l}\text { GIII d } \\
\mathrm{N}=6\end{array}$ \\
\hline $\begin{array}{c}\text { No. of mast } \\
\text { cells/HPF } \\
\pm \mathrm{SD}\end{array}$ & $0.83 \pm 0.75$ & $19.3 \pm 3.8^{\mathbf{\Delta}}$ & $6.67 \pm 1.63^{\bullet \circ}$ & $4.5 \pm 1.044^{-\circ}$ & $3.8 \pm 1.47^{\bullet \circ}$ & $3.2 \pm 1.16^{\bullet \circ}$ \\
\hline
\end{tabular}

SD: standard deviation; N: number of animals

A A significant increase compared with all other groups.

- A significant decrease compared with aspirin-induced ulcer group (GII)

- A significant increase compared with control group (GI). 


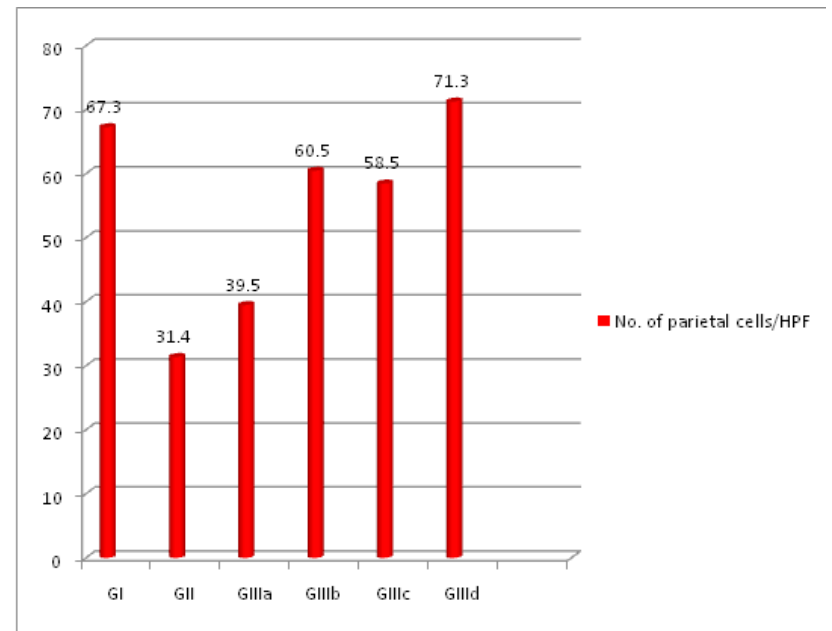

Histogram 1: Number of parietal cells / high power field in rats of the experimental groups

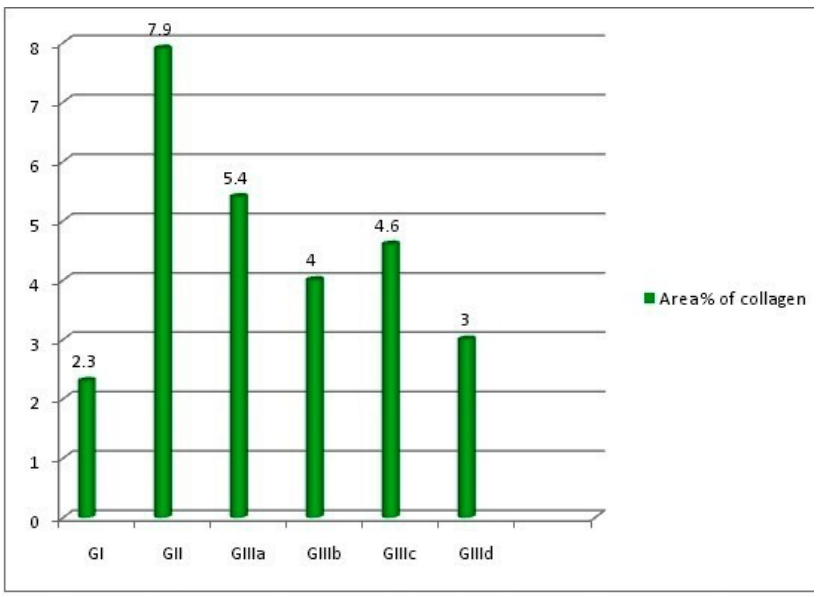

Histogram 2: Area \% of collagen fibers / high power field in rats of the experimental groups

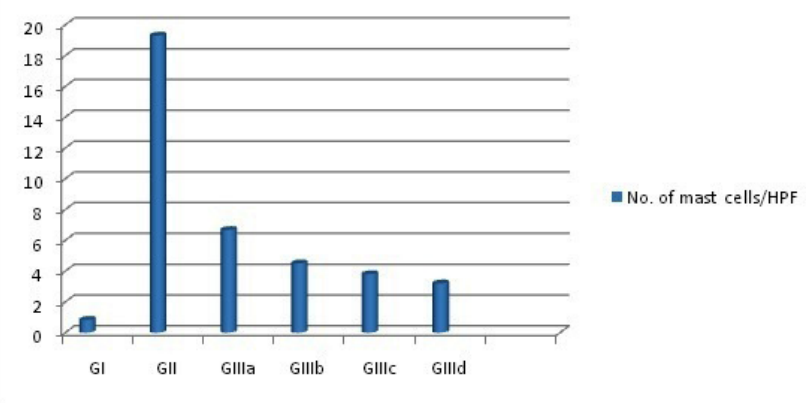

Histogram 3: Number of mast cells / high power field in rats of the experimental groups

\section{DISCUSSION}

Gastric ulcer is a complex pluricausal disease affecting the stomach ending in break in the normal mucosal integrity and is associated with severe complications including haemorrhages, perforations, gastrointestinal (GIT) obstruction, and malignancy ${ }^{[26]}$.
Non-steroidal anti-inflammatory drugs (NSAIDs) are among the most robust efficacy prescribed drugs worldwide in alleviating pain, fever and inflammation. Aspirin, acetylsalicylic acid (NSAID), is almost the most widely used drug either therapeutically or prophylactically to prevent thrombotic events. Despite the advantages of (NSAIDs) but the epidemiologic studies suggest unlimited aspirin usage may be associated with gastrointestinal damage ${ }^{[27,28]}$.

Trio-clar is a recent triple therapy for peptic ulcer. It is a combination of proton pump inhibitors (PPI) mainly omeprazole (OME) with an anti-parasite agent as tinidazole (TNZ) and antibacterial agent as clarithromycin (CLA $)^{[7]}$.

Different studies reported that currently available drugs for treating gastric ulcer showed limited efficacy and posed severe side effects on withdrawal such as relapse, tolerance, nausea and vomiting ${ }^{[29]}$.

Accumulating data has pointed to the gastroprotective effect of medicinal plants in gastric ulcer via inhibiting the gastric acid secretion and boosting the mucosal defence mechanism. These herbal medications could be applied as drugs supplementing or enhancing the activity of synthetic medicines ${ }^{[30,31]}$.

Portulaca aoleracea (purslane) extract may have gastroprotective activity by preventing the oxidative damage of gastric mucosa. The antioxidant property is attributed to its high constituents of gallotannins, omega-3 fatty acids, ascorbic acid, $\alpha$-tocopherols, kaempferol, quercetin, and apigenin ${ }^{[32]}$.

Foeniculum Vulgare Mill (fennel) extract has attracted a great deal of interest among consumers and health care professionals for their potential antiseptic, carminative, lactogogue, diuretic, analgesic and antiinflammatory effects with an anti-ulcer and antioxidant capacity ${ }^{[33]}$.

The present study was carried out to evaluate the cytoprotective effects of trio-clar versus purslane and or fennel on aspirin-induced gastric ulcer in adult female albino rats.

The use of rats in this study as it was routinely used animal model for quick screening of different drugs as clinical studies are limited by ethical and logistic constraints. Moreover, using a gastric tube for drug and herbal extract administration ensured that the accurately calculated dose could exert its maximum effects ${ }^{[34]}$.

The major cause of using female rats in the present study could be justified with the findings of Rashid et al. ${ }^{[35]}$ who stated that peptic ulcer higher prevalence in female was due to unhealthy attitudes towards the eating habits and some stressful environment.

In the current study, the gastric ulcer was induced by oro-gastric administration of aspirin in a dose of 
$300 \mathrm{mg} / \mathrm{kg}$ once daily for 5 days according to the study of Clara et al. ${ }^{[19]}$ who found that marked histopathological changes in the gastric mucosa with ulcer formation observed by using this dose.

The dose of portulaca olarecea $(750 \mathrm{mg} / \mathrm{kg})$ was selected based on the previous work of Samuel et al. ${ }^{[14]}$ and Hassan $^{[15]}$ according to its mean lethal doses (LDs) after acute toxicity. Fennel extract was given in a dose of (300 $\mathrm{mg} / \mathrm{kg}$ ), according to its mean (LDs) after acute toxicity by the effects of metabolite imbalance or nervous system toxicity ${ }^{[16,17]}$. Using herbs either fennel or purslane might be attributed to their phytoestrogen effects ${ }^{[36,37]}$

The data from the present study on body weight showed that the least final body weight was significantly recorded among the aspirin-induced gastric ulcer group (II). On the contrary, body weight was significantly increased among the treated groups, where the highest value was recorded among the combined purslane\& fennel extract-treated group (GIIId) that was more or less as the control group. While the body weight in trio-clar treated rats (GIIIa) was still lower than the herbal extracts treated animals.

The reduction in the bodyweight that was recorded in the ulcerated group is attributed to decreased nutrient digestion and absorption due to the direct irritant effect of aspirin on the gastric and intestinal mucosal cells along with the local inhibitory effects on constitutive cyclooxygenase and gastric prostaglandins(PGE2 and PGI2 ) biosynthesis ${ }^{[38]}$.

Singh et al. ${ }^{[39]}$ stated that anorexia with a gastric ulcer is mainly due to the inflammatory effect of NSAID on the epithelial lining the stomach and intestine. Moreover, Adefisayo et $a l^{[40]}$ added that the anorexia with gastric ulcer was a reflex action to avoid creep friction pain that increased during gastric peristalsis with increasing the area of the ulcer and the amount of gastric acid secretion which collectively stimulates the ulcer and aggravates the pain.

Choosing the upper part of the stomach was according to the previously reported results of Lichtenberger et al. ${ }^{[41]}$ who stated that the body of the stomach is the most common region for gastric ulcers.

The macroscopic brownish hemorrhagic spots and streaks in the gastric mucosa that were observed in aspirininduced gastric ulcer group (II) was attributed to stasis in gastric blood flow, which contributes to the development of the haemorrhages and necrotic aspects of tissue injury ${ }^{[2,43]}$.

The current light microscopic results of aspirininduced gastric ulcer (GII) revealed distorted glandular architecture with widening of gastric pits, ulcerative erosions, sloughing and desquamation of the glandular epithelial lining that appeared shrinked with deeply stained acidophilic cytoplasm and darkly stained nuclei. Vacuolated oxyntic and chief cells with dark stained nuclei along with inflammatory cell infiltrations, congested blood capillaries in the lamina propria between the distorted fundic glands were also observed.
These degenerative changes were going hand to hand with the data reported by Senol et al. ${ }^{[2]}$ and Iwamoto et al. ${ }^{[44]}$. These authors explained aspirin-induced mucosal erosions by local and systemic actions. The pathogenesisrelated to inhibition of cyclooxygenase (COX)-1 and gastric prostaglandins (PGE2 and PGI2) biosynthesis, inhibition of several components of gastric mucosal defence mechanisms mediated by prostaglandins such as reduced mucosal flow, reduced mucus and bicarbonate secretion, and impaired platelet aggregation. The pathogenic mechanisms involved in inhibition of COX-2 are reduction of angiogenesis and increase of leukocyte adherence and subsequent microvascular occlusion. Earlier studies of Konturek et al..$^{[45]}$ stated that aspirin enhanced formation of nitric oxide (NO) which leads to gastric epithelial damage.

The local action of NSAIDs was explained by Hawkins \& Hanks ${ }^{[46]}$ and Akpamu et al..$^{[47]}$ by dispersal of the natural gastro-protective mucous barrier between the underlying epithelial cells and the proteolytic enzymes present in the digestive juice through the direct epithelial damage along with alteration in the quality of the secreted mucus leading to acid back diffusion and injury to the gastric mucosa. Moreover, aspirin increased the volume of gastric juice secretion and total gastric acidity leading to sloughing ulceration of the mucosa ${ }^{[47,48]}$.

Akpamu et al.${ }^{[47]}$ added that the protonophore actions of NSAIDs mainly aspirin, take a significant part in the topical cytotoxic damage on the gastric mucosa. In particular, upon exposure to the acidic environment of the gastric lumen, the un-dissociated lipid-soluble form of aspirin can penetrate cell membranes, segregate within cells, accumulate into epithelial cells and induce osmotic lysis due to uncoupling of oxidative phosphorylation, the enhanced formation of nitric oxide (NO) which leads to gastric epithelial damage

Jambi et al. ${ }^{[49]}$ stated that the necrotic and exfoliated cells of gastric mucosa upon aspirin administration might result from decreased mucosal blood flow by increased deposition of collagen fibers in lamina propria up to marked fibrosis mainly around blood vessels. They also added that erosion may develop, as an ischemic infarct, since the first ultrastructural change is the damage of endothelial basement membrane of the capillary and postcapillary venule leading to the breakdown of small blood vessels before any other cytolytic changes.

Ittiyavirah and Paul ${ }^{[50]}$ added that NSAIDs diminish the binding ability of epidermal growth factor (EGF)-to its receptor leading to inhibition of its signalling pathways with the subsequent inhibition of epithelial proliferation.

Kwiecien et al..$^{[3]}$ and Prakash et al. ${ }^{[51]}$ attributed the widening of the gastric pits, sloughing of mucosal cells into the lumen and a significant reduction in the parietal cells count on aspirin administration to the decreased antioxidant enzymes such as glutathione peroxidase, catalase, and superoxide dismutase with the accumulation of oxygen free radicals and oxidative damage in the cellular 
membrane of gastric mucosa along with mitochondrial failure and translocation of the intramitochondrial protein (apoptosis-inducing factor)ending in cell lysis.

Vacuolation of the parietal cells could be related to the increased secretory canalicular membrane elaboration as a result of increased gastric acid secretion due to loss of the inhibitory effect of prostaglandins on the oxyntic cells ${ }^{[52]}$.

Zhang et al. ${ }^{[53]}$ and Al Asmaria et al. ${ }^{[54]}$ attributed congested blood vessels in the lamina propria of aspirininduced gastric ulcer (GII) to cell death and epithelial exfoliation with exposure of capillaries and venules to the harmful effect of hydrochloric acid in the gastric secretion. They also added that inflammatory cellular infiltration of different kinds of cells mainly mast cells which release histamine led to local vasodilatation, increase capillary permeability and their filtration in the interstitial spaces with subsequent vascular congestion and oedema of interstitial spaces. This was confirmed in the present study by a significant increase in mast cell infiltration in the submucosa in toluidine blue-stained section of the ulcerated group.

Inflammatory cell infiltration in the lamina propria and submucosa of aspirin-induced ulcer might be related to loss of integrity of the intercellular junctions, disturbance of the protective mucus barrier and generation of reactive oxygen species (ROS) with subsequent bacterial invasion which leads to excessive leukocyte infiltration inside the gastric epithelial linings by the activation of interleukin pathway ${ }^{[55,56]}$.

In the present work, the complete absence of alcian blue \& PAS reactions was detected at the distorted ulcerated region despite positive reaction on the adjacent intact mucosa, gastric pits and neck regions along with positive alcian blue reactions at the basal regions of some fundic glands as compared with the control group.

These results were explained by Al-sagaaf et al. ${ }^{[42]}$ and Mohammed \&Mohammed ${ }^{[57]}$. They attributed this to the inhibition of glycoprotein biosynthesis by the epithelial cells due to suppressed PGs production and epithelial damage on long-term administration of aspirin, indicating failure of gastric adaptation against the injurious effects of aspirin.

Iijima et al. ${ }^{[58]}$ explained the increased alcian blue binding capacity at the intact surface mucous coat, gastric pit as well as neck regions by a functional adaptive response in the form of compensatory hyperplasia after aspirin administration.

Additionally, Abdulgawad et al. ${ }^{[31]}$ and Cryer and Mahaffey ${ }^{[59]}$ explained the positive alcian blue at the bases of some fundic glands by the capacity of chief cells to synthesize and store mucous in addition to their serous secretion under stressful circumstances to contribute to the cytoprotective potential of the gastric mucosa against aspirin.
A significant increase in the density and distribution of collagen fibers in the lamina propria in between the distorted fundic glands in the ulcerated group could be explained via Cryer and Mahaffey ${ }^{[59]}$ by the elaboration of the basic fibroblastic growth factor by the infiltrated inflammatory cells attracted to the injured site, which induced fibroblast proliferation and collagen deposition at the site of inflammation.

The ultrastructural changes observed in aspirin-induced gastric ulcer groups (GII) were severely damaged mucus neck cells with a distorted apical part, irregular nuclei with chromatin margination along with vacuolated cytoplasm and distorted intercellular junctions. Distorted parietal cells with dilated perinuclear cisternae, increased density of the mitochondrial matrix, dilated tubulovesicular system with disrupted microvilli which lined the widely dilated intracellular canaliculi and dilated Golgi complex. The distorted chief cell depicted shrunken irregular electrondense nuclei with dilated perinuclear cisternae, markedly dilated rough endoplasmic reticulum, dilated Golgi complex in tubular and vesicular forms and many electronlucent to moderate electron-dense zymogen granules when compared with those of the control group.

These degenerative changes could be explained based on oxidative stress induced by unlimited use of NSAIDs followed by mitochondrial injury, as it promotes progressive mitochondrial damage via changing the mitochondrial inner membrane composition, formation of high conductance channel in the mitochondrial membrane, inhibition of electron transport and /or uncoupling of oxidative phosphorylation, ATP depletion, and induces mitochondrial permeability of cytochrome c from mitochondrial intermembranous space into cytosol and cellular calcium toxicity leading to lipid peroxidation of biological membranes and alterations in the $\mathrm{Na}+/ \mathrm{K}+$ balance which increases cellular permeability to ions disrupting membrane structure ending with weakening of the mucosal barrier and cellular necrosis ${ }^{[55,60]}$.

Seleem et al. ${ }^{[52]}$ stated that the presence of dense bodies, which were secondary lysosomes with disruption of the parietal cell canaliculi is the early signs indicating cellular apoptosis.

Dilatation of rER was referred by Leung et al..$^{[61]}$ as a trial of the cell to increase its surface area which is a compensatory mechanism bearing the function of severely damaged cells. Rubin and Strayer ${ }^{[62]}$ added that deleterious agents might interfere with ATP-dependent $\mathrm{Na}+/ \mathrm{K}+$ pump by increasing the permeability of cell membrane to sodium, thereby exceeding the capacity of the pump to extrude sodium, or damaging the pump itself. Accumulation of sodium in the cell leads to an increase in water content and cell swelling, a condition called hydropic degeneration.

Nuclear changes detected in the present study was likely a representation of cells undergoing apoptotic degeneration secondary to the oxidative damage as a consequence of inflammatory disorder and translocation of the intramitochondrial protein apoptosis-inducing factor ${ }^{[52,61]}$. 
Improvement in histological structure and ultrastructure of the gastric mucosa was detected in the treated groups. Light microscopic examination revealed preservation of the regularly arranged closely packed gastric glands. Nearly normal surface epithelial, mucus neck cells, parietal and peptic cells that were more or less as the control group. Combined alcian blue and periodic acid chief stained sections of the treated groups appeared more or less as the control. Moreover, nearly normal fine collagen fibers in the lamina propria between reconstructed fundic glands, and around blood vessels in the submucosa along with nearly normal mast cells as compared to the control group. Electron microscopic examination confirmed such improvement detected previously.

These improvements were detected among the trioclar (GIIIa), purslane (IIIb), fennel extracts (IIIc) with the best results among the combined purslane $\&$ fennel treated groups (GIIId), despite vacuolation of some parietal and peptic cells along with more prominent alcian blue positive reaction at basal part of the gland in the purslane extract-treated group (IIIb), congestion of blood vessels inbetween the base of the fundic glands and denser collagen fibers in between reconstructed fundic glands and in the submucosa in the trio-clar (GIIIa) and fennel extracttreated group (IIIc). Moreover, partial desquamation of the superficial epithelial lining overlaid the healed gastric ulcer in fennel extract-treated group (IIIc). While the marked improvement of gastric ulcer was detected in combined purslane and fennel group (IIId) where the gastric mucosa appeared more or less near-normal histoarchitecture as shown by light and electron microscopic examination.

The anti-ulcerogenic effects of Triochlar in GIIIa could be attributed to its main components which offered a reliable therapeutic drug, for its well established widely proved ulcer-healing and gastro-protective effects.

A recent study of Jubri et $a l^{[21]}$ and El-Ashmawy et $a l^{[63]}$ stated that omeprazole which is one of the trioclar components is a proton pump inhibitor (PPI). It is considered as an acid anti-secretory agent by its "direct" and "indirect" antioxidant activity along with inhibiting neutrophil activity.

Clarithromycin (CLA) is one of the most useful antimicrobials against helicobacter pylori (H. pylori). It is a well-absorbed acid-stable macrolide antibiotic binds to the 50S ribosomal subunit resulting in inhibition of protein, with a broad spectrum of antibacterial activity. Also, Tinidazole is a most potent member of the nitroimidazole possessing a wide spectrum against anaerobic bacteria as well as protozoa substantially leads to healing of the gastric inflammation, prevention of peptic ulcer, as well as accelerated healing of peptic ulcers, and prevention of ulcer recurrence ${ }^{[64]}$.

According to the current guidelines, triple combination therapy is considered as a standard regimen for the firstline anti-H. pylori treatment despite debates on the ideal duration of treatment. Available data suggest that the duration of PPI-clarithromycin containing triple therapy from 7 to 14 days improves $\mathrm{H}$ pylori eradication by only $5 \%$.

Reduction in the mast cells infiltration in the trio-clar treated group (GIIIa) might attribute to clarithromycin resistance ${ }^{[66]}$.

The anti-ulcerogenic effects of purslane extracts in GIIIb could be attributed to the three active compounds of this plant namely: ergosterol, Lupone and tetracyclic steroid which decreased total gastric acidity through local and systemic action in the stomach either by potent gastric acid anti-secretory effects via antagonizing muscarinic or $\mathrm{H} 2$ receptors or by acid-neutralizing action ${ }^{[8]}$.

Motawi et al.$^{[67]}$ also attributed the anti-ulcerogenic effects of purslane extracts to their abilities to increase gastric mucosal blood flow and mucus production in the gastric lumen, increase in endogenous glutathione and prostaglandin levels and decrease of ischemia, gastric vascular permeability, acid "back diffusion", histamine release, efflux of sodium and potassium, influx of calcium, generation of free radicals and production of leukotrienes.

Kumar et al. ${ }^{[68]}$ and Petropoulos et al..$^{[69]}$ also added that the gastroprotective activity of portulaca oleracea L might be due to the presence of flavonoids namely, kaempferol, $\alpha$-tocopherols, apigenin, myricetin and quercetin along with high constituents of gallotannins, omega-3 fatty acids and ascorbic acid in different parts of the plant which has potent antioxidant properties and prevents the oxidative damage of gastric mucosa.

Increase in the synthesis of mucus might be one of the important contributing cytoprotective factors of P.oleracea L. thereby preventing physical damage and back diffusion of hydrogen ions Oyedeji et al. ${ }^{[70]}$. This was evident by more prominent alcian blue positive reaction at the basal part of the gland and was confirmed ultrastructurally by apparent rounded mucoid granules studded the apices of most of the mucous cells in purslane treated group (GIIIb).

Zaghlool et al ${ }^{[71]}$ added that P. oleracea plant comprises some mucilages which cover and protect the mucosa of the stomach against ulcerative agents.

The gastroprotective effect of fennel extracts in GIIIc could be attributed to bioactive compounds such as flavonoids, tannins, alpha-tocopherol, ascorbic acid, betacarotene and glutathione contents having a wide range of biological mechanisms which lead to increase the mucosal prostaglandin content, decrease histamine secretion, antisecretory action, improve the status of different oxidative stress biomarkers, break radical chain reactions, directly reducing peroxides and free radical scavenging activity that might be associated with the ulcer preventing action ${ }^{[72]}$.

Interestingly, flavonoids are among the cytoprotective materials that increased mucus production and inhibited the helicobacter pylori growth. Anethole also possesses significant antioxidant, anti-inflammatory and ulcer 
healing activity in experimental models ${ }^{[73]}$. Tannins are known to 'tan' the outermost layer of the mucous and render it less permeable and more resistant to a variety of chemical and mechanical ulcerogenic agents ${ }^{[74]}$.

\section{CONCLUSION}

In conclusion, the results of the present study revealed that the therapeutic outcome in aspirin-induced gastric ulcers could be more effective by consuming combined purslane and fennel extracts. The cytoprotective and anti-ulcerogenic effects may be ascribed to the direct antioxidant and free radical scavenging activities and their anti-inflammatory properties. However, further clinical studies are necessary to determine whether they can be applied as therapeutic agents as shown in this preclinical study.

\section{CONFLICTS OF INTEREST}

There are no conflicts of interest.

\section{REFERENCES}

1. Al-Sayed E, Michel HE, Khattab MA, ElShazly M and Singab AN. Protective Role of Casuarinin from Melaleucaleucadendra against Ethanol-Induced Gastric Ulcer in Rats. Plantamedica. 2020; 86(1): 32-44.

2. Senol A, Işler M, Karahan AG, Kilic GB, KuleaşanH, GörenI, Saritaş U, Kaya S, Cırış $\mathrm{M}$, Aktürk $\mathrm{O}$ and Aridoğan BC.Effect of probiotics on aspirin-induced gastric mucosal lesions. The Turkish journal of gastroenterology. The official journal of Turkish Society of Gastroenterology.2011; 22(1):18-26.

3. Kwiecien S, Jasnos K, Magierowski M, Sliwowski Z, Pajdo R, Brzozowski B, Mach T, Wojcik $\mathrm{D}$ and Brzozowski T.Lipid peroxidation, reactive oxygen species and antioxidative factors in the pathogenesis of gastric mucosal lesions and mechanism of protection against oxidative stress-induced gastric injury. J PhysiolPharmacol. 2014; 65(5):613-622.

4. Ibrahim MA, Shazly GA, Elossaily GM, Ezzeldin E and Aleanizy FS.Physicochemical, pharmacokinetics, and histological evaluation of new naproxen-quercetin co-lyophilizate to diminish drug-induced gastric irritations in rats. Saudi Pharmaceutical Journal. 2019; 27(3):413-421.

5. Najm WI.Peptic ulcer disease. Primary Care: Clinics in Office Practice.2011; 38(3): 383-394.

6. Vakil N.Helicobacter pylori treatment: a practical approach. Am. J. Gastroenterol. 2006; 101(3):497-499.
7. Hadad GM,Salam RA and Elkhoudarya MM.Simultaneousdetermination of clarithromycin, tinidazole and omeprazole in helicure tablets using reflectance near-infrared spectroscopy with the aid of chemometry. Pharmaceutica Analytica Acta. 2015; 6(354): 2.

8. Oyedeji $\mathrm{KO}$ andBolarinwa AF.Effects of aqueous and methanol extractsofPortulacaoleracea on gastric acid secretion in male Wistarrats, International Journal of Pharmaceutical Sciences Review and Research. 2016; 38(1):251-255.

9. Kooti W, Ghasemiboroon M, Asadi-Samani M, Ahangarpoor A, Noori Ahmad Abadi M, Afrisham $\mathrm{R}$ and Dashti N.The effects of hydro-alcoholic extract of celery on lipid profile of rats fed a high fat diet. Advances in Environmental Biology. 2014;8(9):325-330.

10. Asadi-Samani M, Kafash-Farkhad N, Azimi N, Fasihi A, Alinia-Ahandani E. and Rafieian-Kopaei M.Medicinal plants with hepatoprotective activity in Iranian folk medicine. Asian Pacific Journal of Tropical Biomedicine.2015b;5(2):146-157.

11. Xin HL, Xu YF, Yue XQ, Hou YH, Li M and Ling CQ. Analysis of chemical constituents in extract from Portulacaoleracea L. with GC-MS Method (In Chinese). Pharmaceut J Chin People's Liberat24. 2008;(2): 133-136.

12. Skulski M.Safe nutritious purslane proves as powerful Drugs. Natuwak News. 2010; 22: 2010.

13. Rather MA, Dar BA, Sofi SN, Bhat BAand Qurishi MA.Foeniculumvulgare: A comprehensive review of its traditional use, phytochemistry, pharmacology, and safety. Arabian Journal of Chemistry .2016;1(9):S1574-S1583.

14. Samuel AB, Michael OE and Edith IE.Evaluating the effects of freeze-dried supplements of purslane (Portulacaoleracea) on blood lipids in hypercholesterolemicadults.Inter. $\mathrm{J}$ of Nutr. and Metab.2011;3(3):43-47.

15. HassanA.Chemical and remedial effects of purslane (portulacaoleracea) plant. Life Sci J.2014; 11(6):31-42.

16. Birdane FM, Cemek M, Birdane YO, Gülçin İand Büyükokuroğlu ME. Beneficial effects of Foeniculumvulgare on ethanol-induced acute gastric mucosal injury in rats. World Journal of Gastroenterology.2007; 13(4):607-611.

17. Al-Snafi AE. The chemical constituents and pharmacological effects of Foeniculumvulgare-A review. IOSR Journal of Pharmacy. 2018; 8(5): 81-96. 
18. Angelo AA, Hassan MA, El Din NMN, Khalifa HM and Ghany SAA. A possible role for gastroprotectives on aspirin-induced gastric ulcer in rats. Alexandria Journal of Medicine. 2010; 46(1):75-82.

19. Clara MV, Puig MN, Castaño SM, OyarzábalYÁ, Molina CV, Hernández NM and MásFerreiro R. Effects of D-002 on aspirin-induced ulcers and neutrophil infiltration on the gastric mucosa. RevistaCubana de Farmacia.2012; 46(2):249-258.

20. Paget GF and Barnes JM. Toxicity tests. In Evaluation of drug activities, pharmacometric. Academic press. 1964; London and New York. Vol.1: pp.135-178.

21. Jubri Z, Rahim NBA and Aan GJ.Manuka honey protects middle-aged rats from oxidative damage. Clinics.2013;68(11):1446-1454.

22. Bancroft JD and Layton C. The hematoxylin and eosin, connective mesenchymal tissues with their stains In: Suvarna SK, Layton $\mathrm{C}$ and Bancroft JD (eds). Bancroft's Theory and practice of histological techniques. (8th edition). 2013; Churchill Livingstone, Philadelphia. pp: 173-212 and 215-238.

23. Prasanna LC, Thomas HR, D'Souza ASand Bhat KM. The histochemical assessment of sulpho-, sialo-, and neutralmucosubstances in fetal gastric mucosa. International Journal of Research in Medical Sciences.2017; 3(1): 235-238.

24. Woods AE and Stirling JW. Transmission electron microscopy. Bancroft's theory and practice of histological techniques.8th edition, Churchill Livingstone, Elsevier, China. 2018; pp.434-475.

25. Emsley R, Dunn G, White IR.Mediation and moderation of treatment effects in randomized controlled trials of complex interventions. Stat Methods Med Res. 2010; 19(3): 237-270.

26. Salama RAA. Investigation on the effect of cannabinoid agonists and antagonists in gastric acid secretion and gastric ulcer in rats. CU Theses.2019; 4-11.

27. Brune $K$ and Patrignani $P$. New insights into the use of currently available non-steroidal anti-inflammatory drugs. Journal of pain research. 2015;2015(8):105-118.

28. Ajayi AF, Aniviye BO, Kehinde BD and Akintola AO.Age-related Changes in the Expression of Heat Shock Protein 70 and 90 on the Gastric Mucosa During Gastric Ulcer Healing. UK Journal of Pharmaceutical and Biosciences. 2018; 6(4): 01-10.

29. Atchison JW, Herndon CM and RusieE. NSAIDs for musculoskeletal pain management: current perspectives and novel strategies to improve safety. Journal of Managed Care Pharmacy. 2013; $19(9$ Supp A):1-19.

30. Ayala G, Escobedo-Hinojosa WI, de la Cruz-HerreraCFandRomeroI.Exploringalternative treatments for Helicobacter pyloriinfection. World J Gastroenterol. 2014;20(6):1450-1469.

31. Abdulgawad HS, HasaneinMA, Header EA influence of aqueous extract of Red Chillis pepper as curative for gastric ulcer in albino rats. J Nat Sci Res. 2013; 3(4):78-87.

32. Zhu H, Wang Y, Liu Y, Xia Y and Tang T.Analysis of flavonoids in Portulacaoleracea L. by UV-vis spectrophotometry with comparative study on different extraction technologies. Food Analytical Methods. 2010; 3(2):90-97.

33. Al-Mofleh I, Al-Sobaihani M, Alqasoumi S, Al-Said M, Al-Dosari M, Al-Yahya M and Rafatullah S.Fennel" Foeniculumvulgare" treatment protects the gastric mucosa of rats against chemically-induced histological lesions. Int J Pharm. 2013; 9(3):182-189.

34. Elgarawany GE, Ahmed FE, Tayel SI and Soliman SE.Effect of Garlic in Comparison with Misoprostol and Omeprazole on Aspirin Induced Peptic Ulcer in Male Albino Rats.Der PharmaChemica. 2017; 9(6):68-74.

35. Rashid MN, Soomro AM, Channa NA and Laghari ZA. Prevalence of different types of peptic ulcer disease and treatment modalities used by patients in Hyderabad. Pakistan Journal of Physiology. 2016;12(1):6-9.

36. Helal EG, Jalaud AL, Abdul-Aziz N, El-Aleem MA and Ahmed SS. Effect of phytoestrogen (Fennel) on some sex hormones and other physiological parameters in male albino rats. The Egyptian Journal of Hospital Medicine.2019; 74(7): 1616-1620.

37. Di FG and Petropoulos SA. Phytoestrogens, phytosteroids and saponins in vegetables: Biosynthesis, functions, health effects and practical applications. Advances in food and nutrition research. 2019; 90:351-421.

38. Katherine AS, Niamh MM and Steve RB Hypothalamic regulation of appetite. Rev. Expert review of endocrinology \& metabolism. 2008; 3(5):577-592.

39. Singh DP, Borse SP and Nivsarkar M.A novel model for NSAID induced gastroenteropathy in rats. Journal of pharmacological and toxicological methods. 2016;1(78):66-75. 
40. Adefisayoa MA,Akomolafeb RO, Stephen O,AkinsomisoyebSO,Alabib QK,Ogundiped OL,Omoleb GJand Olamilosoyeb KP. Gastro-protective effect of methanol extract of Vernoniaamygdalina (del.) leaf on aspirin-induced gastric ulcer in Wistar rats.Toxicology Reports. 2017; 4: 625-633.

41. Lichtenberger LM. The hydrophobic barrier properties of gastrointestinal mucus. Annu. Rev. Physiol.2005; 17 (3):178-188.

42. Al-sagaaf S, Ramadan WS and Abunasef SK. Does commercial aloe vera protects the structure of the gastric mucosa against acute nonsteroidal anti-inflammatory drug (diclofenac sodium)induced damage? Egyptian Journal of Histology. 2011; 34(1):80-91.

43. Kolawole I A and Francis SO.Effects of a type $\mathrm{V}$ phosphodiesterase inhibitor (tadalafil) on indomethacin-induced gastric ulceration in rats. International Journal of Tropical Medicine. 2012; (3):111-116

44. IwamotoJ,SaitoY,HondaAandMatsuzakiY.Clinical features of gastroduodenal injury associated with long-term low-dose aspirin therapy. World journal of gastroenterology.2013;19(11):1673-1682.

45. Konturek PC, Kania J, Hahn EG and Konturek JW.Ascorbic acid attenuates aspirin-induced gastric damage: role of inducible nitric oxide synthase. J. Physiol. Pharmacol.2006;1(57):125-136.

46. Hawkins $\mathrm{C}$ and Hanks GW.The gastroduodenal toxicity of nonsteroidal anti-inflammatory drugs.A review of the literature.Journal of pain and symptom management.2000;20(2):140-151.

47. Akpamu U, Owoyele VB, Ozor M and Osifo UC.Indomethacin-induced gastric ulcer: model in female Wistar rats. International Journal of Basic, Applied and Innovative Research. 2013; 2(4):78-84.

48. D'Argenio G, Mazzone G, Tuccillo C, Grandone I, Gravina AG, Graziani G, Fogliano V and Romano M. Apple polyphenol extracts prevent aspirininduced damage to the rat gastric mucosa. British journal of nutrition. 2008; 100(6):1228-1236.

49. Jambi HA and Khattab HAH. Potential antioxidant, anti-inflammatory and gastroprotective effect of grape seed extract in indomethacin-induced gastric ulcer in rats. Int J Pharmacol.2019; 1(15):209-218.

50. Ittiyavirah SP and Paul AS.Gastroprotective effect of plumbagin and ethanolic extract of plumbaginales in experimentally-induced ulcer. Journal of Herb Med Pharmacology. 2016; 5(3): 92-98.
51. Prakash M, Balamurugan M, Parthasarathi K, Gunasekaran G, Cooper E and Ranganathan L.Anti-ulcer and anti-oxidative properties of 'earthworm paste' of Lampitomauritii (Kinberg) on Rattusnorvegicus. Eur Rev Med PharmacolSci.2007;11: 9-15.

52. Seleem HS, Ghobashy HA and Zolfakar AS.Effect of aspirin versus aspirin and vitamin $\mathrm{c}$ on gastric mucosa (fundus) of adult male albino rats. histological and morphometric study. Egyptian Journal of Histology.2010; 33(2):313-26.

53. Zhang JY, Wu QF, Wan Y, Song SD, Xu J, Xu XS, Chang HL, Tai MH, Dong YF and Liu C.Protective role of hydrogen-rich water on aspirin-induced gastric mucosal damage in rats. World Journal of Gastroenterology. 2014; 20(6):1614.

54. Al Asmaria A, Al Shahranib H, Al Masric N, Al Faraidid A, Elfakia I and Arshaduddina M.Vanillin abrogates ethanol induced gastric injury in rats viamodulation of gastric secretion, oxidative stress and inflammation. Toxicology Reports. 2016;1(3):105-113.

55. Yehia NM, Salam NFA, Saleh HA and Bayomi NS.Effect of $\alpha$-lipoic acid on fundic gastric mucosal damage induced by acetyl salicylic acid: a histological study. Egyptian Journal of Histology.2014; 37(2):280-291.

56. Savaringal JP and Sanalkumar KB.Anti-ulcer effect of extract of rhizome of Curcuma longa. $\mathrm{L}$ against aspirin-induced peptic ulcer in rats. National Journal of Physiology, Pharmacy and Pharmacology. 2018; 8(5):650-657.

57. Mohammed JAH and Mohammed SA.In vivo Hepato-protective Properties of Purslane Extracts on Paracetamol-Induced Liver Damage. Malaysian journal of nutrition. 2010; 16(1):161-170.

58. Iijima $\mathrm{K}$, Ara $\mathrm{N}$, AbeY, Koike $\mathrm{T}$, Iwai W, Iwabuchi T, Ichikawa T, Kamata Y, Ishihara K and Shimosegawa T. Association of gastric acid and mucus secretion level with low-dose aspirininduced gastropathy. Journal of gastroenterology. 2012; 47(2):150-158.

59. Cryer B and Mahaffey KW.Gastrointestinal ulcers, role of aspirin, and clinical outcomes: pathobiology, diagnosis, and treatment. J Multidiscip Healthcare. 2014; 3(7): 137-146.

60. Selim MM, Elshal EB and Elwahab AHA. Effect of ellagic acid on gastric mucosa of experimentally induced gastric ulcer: Histological and immunohistochemical study. EJPMR.2016; 3(12):658-667.

61. Leung AM, Redlak MJ, Miller TA.Aspirininduced mucosal cell death in human gastric cells: role of a caspase-independent mechanism. Dig. Dis. Sci.2009;54(1):28-35. 
62. Rubin R and Strayer DS. Rubin's Pathology: Clinicopathologic Foundations of Medicine. 6thedition. 2012; Lippincott Williams \& Wilkins. Philadelphia.pp:14-15.

63. El-Ashmawy NE, Khedr EG, El-Bahrawy HA and Selim HM.Gastroprotective effect of garlic in indomethacin induced gastric ulcer in rats. Nutrition. 2016; 32(7-8):849-854.

64. Leung WK and Graham DY.Clarithromycin for Helicobacter pylori infection.Expert opinion on pharmacotherapy. 2000; 1(3):507-514.

65. Riquelme A, Soza A, Pedreros C, Bustamante A, Valenzuela F, Otarola F, Abbott E, Arellano M, Medina B, Pattillo A and Greig D.Optimal length of triple therapy for $\mathrm{H}$ pylori eradication in a population with high prevalence of infection in Chile. World journal of gastroenterology. 2007; 13(21):2967-2972.

66. Bhattamisra SK, Hooi LP, Shyan LP, Chieh LB, Candasamy $\mathrm{M}$ and Sahu PS.Effect of geraniol and clarithromycin combination against gastric ulcers induced by acetic acid and Helicobacter pylori in rats. Pharmacognosy Research. 2019; 11(4):356.

67. Motawi TK, Hamed MA, Hashem RM, Shabana $\mathrm{MH}$ and Ahmed YR.Protective and therapeutic effects of Argyreiaspeciosa against ethanol-induced gastric ulcer in rats. Zeitschriftfürnaturforschung. 2012;67(1-2):47-57.

68. Kumar CA, Tejasri M, Kumar DS, Ramya M, Revathi Kand Reddy GAK.A review on antioxidants. Innovative Drug Discovery. 2012; 2(2): 98-114.

69. Petropoulos SA, Karkanis A, Fernandes Â, Barros L, Ferreira IC, Ntatsi G, Petrotos K, Lykas C and
Khah E.Chemical composition and yield of six genotypes of common purslane (Portulacaoleracea L.): an alternative source of omega-3 fatty acids. Plant foods for human nutrition. 2015; 70(4):420-426.

70. Oyedeji KO, Bolarinwa $\mathrm{AF}$ and Oladosu IA. Effect of isolatedergosterol constituent of Portulacaoleracea on reproductiveparameters in male rats, International Journal of Pharmacy andPharmaceutical Sciences.2013a; 5(2):702-708.

71. Zaghlool SS, Abo-Seif AA, Rabeh MA, Abdelmohsen UR and Messiha BA.GastroProtective and Anti-Oxidant Potential of Althaeaofficinalis and Solanumnigrum on Pyloric Ligation/Indomethacin-Induced Ulceration in Rats. Antioxidants. 2019; 8(11): 512-543.

72. Palacios-Espinosa JF, Arroyo-García O, García-Valencia G, Linares E, Bye R and Romero I.Evidence of the anti-Helicobacter pylori, gastroprotective and anti-inflammatory activities of Cupheaaequipetala infusion. Journal of ethno pharmacology. 2014;151(2):990-998.

73. Yang W, Lu J, Weng J, Jia W, Ji L, Xiao J, Shan Z, Liu J, Tian H,Ji Q and Zhu D.Prevalence of diabetes among men and women in China. New England journal of medicine. 2010; 362(12):1090-1101.

74. Richard DK, Jauro A, Nvau JB and Dabun LJ.Ethanol-induced gastric ulceration in rats: Protective roles of methanol and water extracts of Cyathulaprostrata Linn Blume. Journal of Pharmacognosy and Phytochemistry. 2017; 6(5):1515-1517. 
الملخص العربى

\title{
تأثير عقار التريو كلار مقابل تناول مستخلص الرجلة و / أو الثمر على القرحة

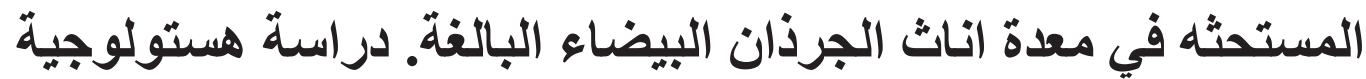

\author{
اماني مصباح محمد على، سعاد كمال محمد عبد الجواد، رحاب عبد الله حسن، منى محمد عبد الجليل \\ قسم الهستولوجيا ـ كلية الطب (بنات)- جامعة الازهر
}

مقدمة: قرحة المعدة هي مرض معقد يصيب المعدة. يعد استخدام الأدوية المضادة للالتهابات غير الستيرويدية (مضادات

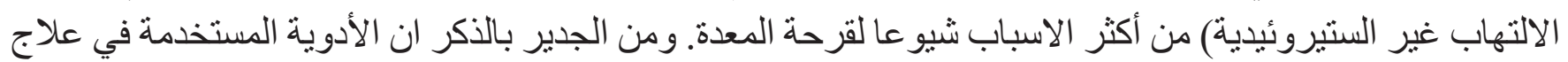

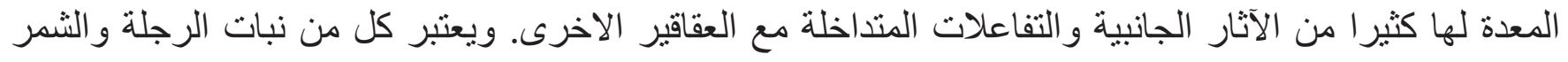

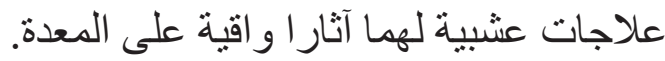
الهدف من البحث: تقييم الدور الوقائي لعقار ثلاثي كلار مقابل الرجلة او مع الثمر على قرحة المعدة المستحثة

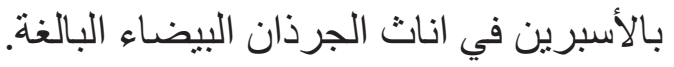

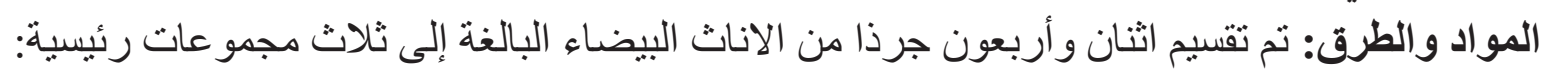

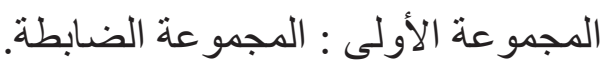
المجمو عة الثانية : المجمو عة المصابة بقرحة المعدة, حيث تم إعطاء الجرذان الصائمة محلول الأسبرين ( . . ب مجم/ كجم يو مبا) عن طريق الفم بواسطة أنبوب معدي المجمو عة الثالثة :أدرجت كمجمو عة قرحة المعدة المعالجة ، و التي تم تقسيمها بالتساوي إلى أربع مجمو عات فرعية المجمو عة GIII a: مجمو عة قرحة المعدة المعالجة بعقار ثثلاثي كلار.

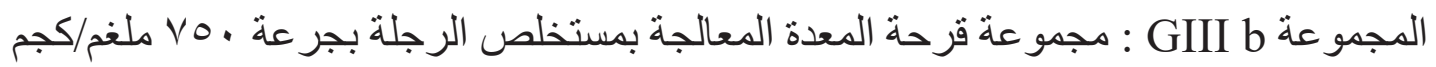

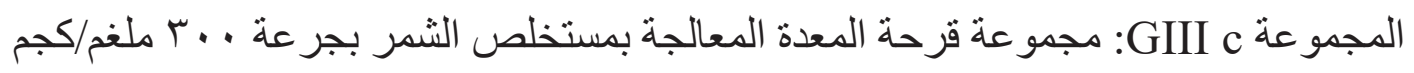

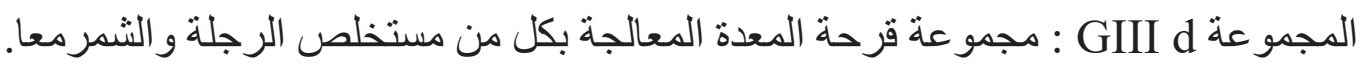

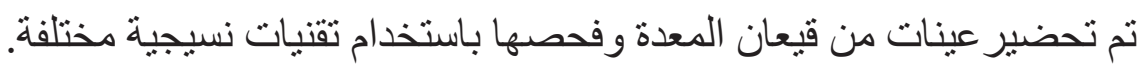
النتائج: أظهر الفحص المجهري لمجموعة قرحة المعدة المستحثة بالأسبرين إصابة حادة في الطبقة المخاطية للمعدة

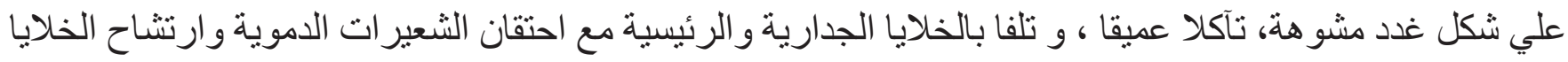

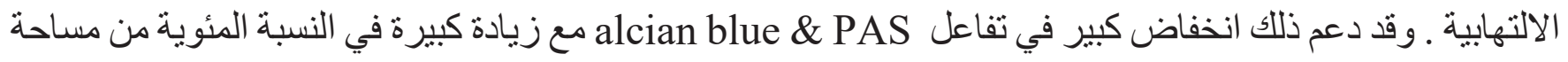

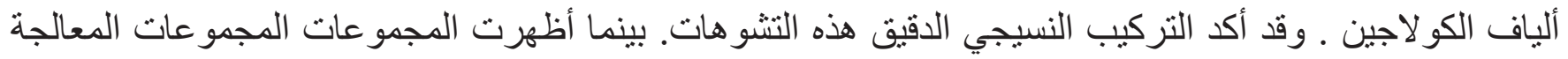

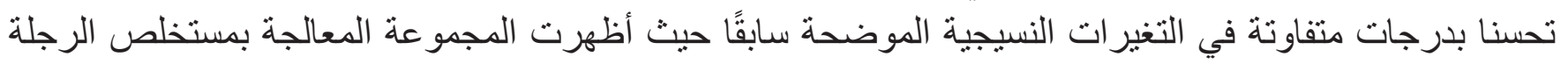
و الثمر معا افضل النتائج. خلاصة البحث: كان للجمع بين مستخلص الرجلة والثمر الثمر أكثر فعالية في تعزيز عملية الثفاء بخلاف مستخلص الرجلة، أو الثمر منفردا أو بعقار ثناثي كلار. 